\title{
Implementation and validation of the Simple Lateral Mechanism Analysis (SLaMA) for the seismic performance assessment of a damaged case study building
}

\author{
CIRO DEL VECCHIO ${ }^{1 \dagger}$, ROBERTO GENTILE ${ }^{2}$, MARCO DI LUDOVICO $^{1}$, GIUSEPPINA \\ $\mathrm{UVA}^{2}$, STEFANO PAMPANIN ${ }^{3}$ \\ ${ }^{1}$ Dept. of Structures for Engineering and Architecture, University of Napoli “Federico II”, Napoli, Italy \\ ${ }^{2}$ Dept. DICATECh, Politecnico di Bari, Bari, Italy \\ ${ }^{3}$ Dept. of Structural and Geotechnical Engineering, University of Rome "La Sapienza", Rome, Italy; Dept. of Civil and \\ Natural Resources Engineering, University of Canterbury, Christchurch, New Zealand
}

$†$ Address correspondence to Ciro Del Vecchio, Dept. of Structures for Engineering and Architecture, University of Napoli "Federico II", via Claudio 21,80125 Napoli, Italy. E-mail: ciro.delvecchio@unina.it

\begin{abstract}
The new guidelines for the seismic assessment of existing buildings recently introduced by the New Zealand Society for Earthquake Engineering (NZSEE) recommend the Simple Lateral Mechanism Analysis (SLaMA) as an "analytical" first phase of any other numerically-based analysis. This paper illustrates the development of the SLaMA method and its validation with reference to an existing RC building severely damaged during the Christchurch earthquake (2011). The capacity of the lateral resisting systems is assessed from component/subassembly to system level. The comparison of results with observed damage and with the outcomes of refined numerical analyses confirms the effectiveness of this method.
\end{abstract}

Keywords: Displacement-Based, Assessment, Reinforced Concrete, NZSEE guidelines, Hierarchy of Strength, Nonlinear analysis. 


\section{Introduction}

Recent seismic events have confirmed the high vulnerability of existing non-ductile reinforced concrete (RC) buildings, further highlighting the influence of structural weaknesses on the global seismic capacity. The premature failures of poorly detailed primary structural members such as beams, columns, beam-column joints, structural walls or gravity load-dominated columns may significantly compromise the overall building response [Calvi et al. 2002; Kam et al. 2011; Leon et al. 2014; Del Vecchio et al. 2016]. This led, in some unfortunate cases, to the building collapse [Kam et al. 2011]. The significant damage and the related costs in many cases compromised the building reparability [Kam et al. 2011; Ligabue et al. 2017; Di Ludovico et al. 2017a; b].

Refined non-linear modelling procedures are nowadays available. However, despite of the implementation in user-friendly commercially available software, difficulties still arise in the definition of reliable capacity curves and interpretation of the results. Although non-linear analyses are arguably considered the most refined tools for the seismic assessment of existing buildings, their accuracy strongly depends on the ability of the numerical model to capture the probable failure mechanism. Thus, there is an urgent need for reliable seismic assessment procedures allowing for the simple identification of the potential structural weaknesses and their influence on the overall building capacity.

An attempt to provide a seismic assessment methodology able to identify the most critical collapse mechanism accounting for the structural weaknesses typical of poorly detailed members was made by Priestley and Calvi [1991]. As result of a revision of the earlier approaches [Park 1997; Paulay and Priestley 1992; Priestley et al. 1996], a Displacement-Based Assessment (DBA) methodology was proposed by Priestley [Priestley 1995, 1997] focusing on the displacement capacity of critical components, recognized as better indicator of the seismic performance of a structure. Such an approach was later developed in detail [Priestley et al. 2007], including experimentally validated formulation for the member's capacity, a step-by-step design procedure 
and a proposal for the application in the current standard. Recently, significant advances were made to address the simplified calculation of earthquake losses [Borzi et al. 2008] or introducing the influence of stiff-infills in existing RC structures typical of European building stock [Cardone and Flora 2017; Landi et al. 2016].

The displacement-based design approach is proposed as an alternative to force-based methodologies in current code of practice [NZS 3101 2006]. However, the lack of explicit references to capacity models or step-by-step guidelines did not promote its application. To fulfil this gap, the New Zealand Society for Earthquake Engineering (NZSEE) developed detailed guidelines for the "Assessment and Improvement of the Structural Performance of Buildings in Earthquakes" [NZSEE 2006]. Within inelastic methods of analysis that can be used for a Detailed Seismic Assessment (DSA), the Simple Lateral Mechanism Analysis (SLaMA) was proposed along with detailed capacity models to characterize the member's lateral response considering all the possible failure modes. Furthermore, in order to improve the communication of seismic risk of the reference building to the stakeholders, a grading system (A+ to F) reflecting the earthquake risk of the construction was proposed based on the building capacity at the ultimate limit state as a percentage of the New Building Standard (\%NBS). The NZSEE [2006] guidelines have been superseded by a significantly revamped new document "The Seismic Assessment of Existing Buildings" [NZSEE/MBIE 2016a; b; c]. Significant effort has been dedicated to the improvement and comprehensive discussion of the features of the new SLaMA method, an analytical (basically 'by hand') approach, which is strongly recommended (and endorsed) as the first phase of any numerically-based analysis. The objective is to avoid embarking into sophisticated techniques without first developing an understanding of how the building resists seismic loads and identifying the various critical load paths and how the various systems might interact. The multi-level assessment approach suggested in the NZSEE [2017] guidelines matches with other approaches available in international codes [ASCE/SEI 2007; ATC 50 2012; ATC 2015]. The NZSEE 2017 
represents the key implementation tool for a mandatory national plan for seismic risk reduction, taking effect in New Zealand from the $1^{\text {st }}$ July 2017 [2017].

This paper illustrates the recent developments of the SLaMA procedure for the detailed seismic assessment of existing buildings. The methodology and the theoretical considerations made to simplify the available literature approaches are herein reported and discussed. The applicability and accuracy of the procedure are discussed with reference to an existing RC building severely damaged during the Christchurch earthquake (2011, New Zealand). The step-by-step-procedure, is demonstrated from a component level (beams, columns, wall elements) to a subassembly level (hierarchy of strength in a beam-column joint) and to a system level (frame, C-Wall) assuming initially a $2 \mathrm{D}$ behaviour of the key structural systems, and then incorporating a by-hand 3D behaviour (torsional effects). The comparison with the results of refined numerical static (pushover) and dynamic (NLTH) analyses and with the observed damage represents both an input and an output (validation check) of the latest procedure published in the NZSEE guidelines [NZSEE/MBIE 2016c]. The good match confirmed that SLaMA can be a useful and simple tool to have a first estimation of the building lateral response. It allows to identify the main structural weaknesses driving the user to the development of more refined nonlinear models.

Worth noting that the application of the SLaMA Method and of the overall NZSEE guidelines to case study buildings, as presented in this paper, has been instrumental to the continuous development and refinement of the analytical procedure through the various drafting phases.

\section{Main principles of the Simple Lateral Mechanism Analysis (SLaMA)}

SLaMA is an analytical (or 'by hand') non-linear analysis technique that provides an estimate of the probable global capacity (force-displacement) of the primary lateral structure of the building by considering the probable capacities of the individual mechanisms/systems. It is a simple methodology relying on the main assumptions and further developments and integration of the Displacement-Based Assessment [Priestley 1997]. This allows the use of simplified capacity 
models and, hence, all the calculations can be performed "by hand". Numerical computer model is not needed and all the calculations can be easily implemented in an electronic spreadsheet. The basic idea is to progress "from local to global" to retrieve an estimate of the probable capacity curve of a building (base shear vs deformation) by extending the local behaviour of the structural members to the global pushover response.

Significant effort has been dedicated to provide within the NZSEE 2017 guidelines [2016c] a step-by-step description of the procedure, either in general terms as well as with specific reference to Reinforced Concrete Buildings (Chapter 5). The step-by-step-procedure is summarized in Fig. 1. In this paper, all the steps from the definition of the structural capacity to the comparison of the Capacity vs. Demand will be addressed with reference to the case study building. In particular, the structural capacity will be herein computed using the SLaMA approach from a component level (beams, columns, wall elements) to a subassembly level (hierarchy of strength in a beam-column joint) and to a system level (frame, C-Wall) assuming initially a 2D behaviour of the key structural system, and then incorporating a by-hand 3D behaviour (torsional effects).

In particular:

- Structural Capacity (Vulnerability): Assessing the lateral capacity of the building in terms of capacity curve (push-over) by using the SLaMA procedure described in detail at the concrete chapter (Ch5) of the NZSEE/MBIE guidelines [2016c]. This goal can be achieved starting from the building data collection (geometry, material properties and structural details, key structural elements and potential structural weaknesses) which allows the estimation of (a) the probable component capacity in terms of moment-drift accounting for all the possible failure modes (flexural, shear, lap splice, etc.). At subassembly level (b), the probable inelastic behaviour of elements is evaluated by comparing probable member capacities with a hierarchy of strength approach [Pampanin et al. 2007]. 
At the structural system level (c), a 'fuse' of capacity curves can be obtained considering a beam sidesway and column sidesway mechanisms (representing the upper and lower bound of the actual frame capacity, respectively) and the more likely mixed sidesway mechanisms (given by the actual strength hierarchy at subassembly level). The probable strength and the variability of material properties (uncertainties) should also be properly accounted for in the evaluation of the local hierarchy of strength. Once the capacity curves of the lateral resisting systems are estimated, they can be combined in parallel in each directions - thus assuming equal displacement demand - to assess the $2 \mathrm{D}$ building lateral capacity in each of the principal directions. The (3D) torsional effects are also considered with a simplified approach.

- Demand (Hazard): Evaluating the seismic demand (Hazard) through the AccelerationDisplacement Response Spectrum (ADRS) accounting for site effects;

- Capacity vs. Demand (Performance): Evaluating the performance point(s) through the intersection of the capacity curve with spectra corresponding to different intensity levels. . According to the Displacement-Based approach, the equivalent viscous damping is considered to modify the ADRS curve. The \%NBS (\% New Building Standard) is the primary seismic safety/risk index adopted by the NZSEE and represent the ratio between the Capacity (at Ultimate Limit State, ULS, or Life Safety, LS) of the existing building and the Demand (of a newly design building on the same site). In practical sense, it can be evaluated scaling down (most likely) the ADRS spectrum until reaching the (displacement) capacity (at ULS or LS).

With reference to the first proposal of the SLaMA methodology available in the NZSEE guidelines [2006], several advances and developments to the vulnerability assessment of RC buildings are made and validated by using the results of this case study building. A direct comparison between analytical predictions, observed earthquake damage and the results of refined numerical models has been useful to solve the main criticisms of SLaMA. This was made at component, subassembly, system and building level. In particular, an in depth description of experimentally validated capacity 
models for RC columns, beams and beam-column joints has been included basing on experimental evidence and analytical studies [Calvi et al. 2002; C. Del Vecchio et al. 2017; Del Vecchio et al. 2018]. An overview of the capacity models suggested in the NZSEE/MBIE guidelines [2016c] and briefly summarized in Table 2 . This allows the user to account for non-linear phenomena typical of poorly detailed RC members, such as bar buckling, flange effects, flexural-shear interaction, shear failure of short or gravity load columns, the joint non-linear behavior after the first cracking. Properly developed formulations to account for the different failure mechanisms in a strength hierarchy framework are proposed as reported in Table 3. This allows for the identification of the structural weaknesses at subassembly level accounting for the influence of axial load due to the seismic shaking [Pampanin et al. 2007]. Available simplified formulations to assess the effective height of for different failure mechanisms of RC frames [NZSEE 2006; Priestley 1997] have been assessed and included in the guidelines. Furthermore, a simplified approach, described herein, has been developed to assess the response of wall-frame dual system.

While providing a complete demonstration of the overall procedure, few examples of detailed analytical calculations for selected structural components will be herein given. Results of key parameters (strength and deformations) of all elements, necessary to derive the global mechanism, are also provided.

\section{Case study building}

The case study building is a 8-storey RC building (Securities House, located at 221 Gloucester Street) which was used as commercial office before February 2011, when the Canterbury Earthquake occurred. It was built in 1974 and designed when Capacity Design principles and comprehensive seismic details had not been introduced yet. It is worth noting that, although Capacity Design was officially introduced in the New Zealand code in 1976 [MOW 1976], improved detailing were already included in some by-laws (early 1970s, [MOW 1968]) and this design example reflects somehow an example of good practice of the day. Well-detailed columns 
and beam-column joints and a rough capacity design (by requiring flexural strengths of columns at a beam column joint to exceed the corresponding sum of the beam flexural strengths) were in fact clearly implemented.

The selected building is part of the ensemble of buildings inspected in the aftermath of the Christchurch 2011 earthquake. A general overview of the building performances grouped in building classes is reported in Pampanin et al. [Pampanin et al. 2012] along with a discussion on the common structural weaknesses. Details on the building geometry, structural configuration, reinforcement details and detected damage are reported in Pampanin et al. [Pampanin et al. 2012] and Del Vecchio et al. [2017].

As shown in Fig. 2, where basic plan and elevation views are reported, the building structural systems consist of:

- a reinforced concrete frame in the longitudinal direction (N-S or Y-direction, indicated as Frame 1);

- reinforced concrete perimeter frame systems in the transverse direction (E-W or X-direction, indicated as Frame A and Frame D);

- a C-shaped reinforced concrete structural wall and an inner L-shaped singly reinforced concrete walls with mesh on the east side of the building (where staircases are located);

- Interior gravity columns in the central part of the building.

The building, thus, presents a combination of frames and a core wall located on the east side (staircase), leading to strength-stiffness eccentricity and potential inelastic torsion effects.

In the Y-direction, the wall web is connected to exterior columns by framing beams creating a symmetric dual system. Even though the two wall flanges in the X-directions have the role to supports the flat slab, their contribution to the lateral building stiffness cannot be neglected. 
The foundation system consists of single footings with piles for columns, connected by slender foundation beams/strips and foundation deep beams with piles for the walls. The footings are all connected via shallow foundation beams.

Plan and elevation view of the critical structural systems are shown in Fig. 2. The building has a regular shape but unbalanced resisting systems due to the location of the C-shape wall (staircase) on the east side with no counterpart on the west facade.

The pre-stressed 5" (127 mm) RC flat slab was casted in-situ. Along the inner grids 2 and 3 connecting interior columns, the slab thickness was increased to 10" (254 mm) for a width of about $1 \mathrm{~m}$. Perimeter frames resist the lateral seismic actions. Frame 1 and the dual system (wall + frame) resist the lateral force in the longitudinal direction, $\mathrm{Y}$, and frames $\mathrm{A}$ and $\mathrm{D}$ resist the lateral force coming along the transverse direction, $\mathrm{X}$. The $\mathrm{C}$-shaped reinforced concrete wall, thus, contributes to lateral resistance in both directions.

A description of the observed damage to the building following the 22 Feb 2011 Christchurch earthquake can be found in [Pampanin et al. 2012]. The building suffered for severe structural damage and, in the aftermath of the Canterbury sequence, it was Red-tagged and consequently demolished.

As shown in Fig. 3, the damage was mostly concentrated in the frames, with limited damage to the structural walls. The overall mechanism in the frame was a mixed sway, comprising, in general, a combination of beam flexural hinging in the exterior beam-column joints, shear damage in the interior joints and shear failure in some columns at the level 1 (first suspended floor) due to the interaction with the deep spandrel/frame beams. This interaction prevented the joint panel shear failure leading to the shear failure of upper "short" columns.

\section{Material Properties and Reinforcement details}


According to NZSEE/MBIE [2016c] guidelines, as a starting point and in the absence of further direct information, default values on the mechanical properties of the reinforcing steel can be assumed in accordance with standards at the time of construction.

In this case the structural drawings report (specified) material properties, as shown in Fig. 4.

The concrete compressive strength (at 28 days on standard cylinders) specified in the design drawings is about $3500 \mathrm{lb} \mathrm{sq} / \mathrm{in}=24.1 \mathrm{MPa}$.

As mentioned in the NZSEE [2016c] guidelines, an overstrength/aging coefficient of 1.5 could be used to evaluate the probable compressive strength of the concrete.

However, in the absence of more direct information on the material at the time of construction and/or at the time of the assessment, it is herein felt than using a probable compression strength $f_{c}^{\prime}=30 \mathrm{MPa}$ for the DSA procedure would possibly be on the higher and non-conservative side especially when looking at shear-related mechanism.

In real practice, it would be highly suggested to retrieve more reliable information from on-site material testing, specifically if/when shear failure in elements/subassemblies can be triggered when considering low-strength concrete values.

In order to account for the high variability of concrete material properties commonly found in pre70's cast-in-situ buildings due to a lower quality control checks/measurements when compared to today's requirement, the probable concrete compression strength is herein assumed as $25 \mathrm{MPa}$. This would correspond to either a $-20 \%$ variation from the probable value calculated as $1.5 \cdot f^{\prime} c$ or to the assumption of a lower, but still realistic, class of concrete (concrete compressive strength of 17.2 $\mathrm{MPa}$ ) and same aging coefficient.

According to the drawings, deformed bars Grade 275 (40 ksi) were adopted.

Probable material properties herein used for the assessment are summarised in Table 1. 
They are computed multiplying the nominal strength $(5 \%$-ile or characteristic values) by the coefficients 1.5 and 1.08 , as suggested in the guidelines for concrete and steel, respectively, and applying the aforementioned judgement on the concrete strength.

The other basic concrete material properties are computed: concrete tensile strength $\left(f_{c t}=0.36\left(f^{\prime}{ }^{\prime}\right)^{1 / 2}=1.83\right)$ and concrete elastic modulus (NZS 3101:2006 5.2.3, $\left.E_{c}=3320\left(f^{\prime}{ }^{\prime}\right)^{1 / 2}+6900\right)$.

The NZSEE guidelines also suggests to account for the effects of variation of material strength when evaluating the hierarchy of strength. The variations considered in this study are $\pm 20 \%$ of the probable value of concrete strength.

The reinforcement details were identified using the original drawings available for the selected case study. Examples of the reinforcement details of beams and columns are reported in Fig. 5 and Fig. 6 , respectively.

The beam longitudinal reinforcements consist of $\phi 24$ and $\phi 20$ deformed bars (namely D24 and D20 in the design drawings, respectively) anchored $90^{\circ}$ in the joint core. The reinforcement amount significantly varies floor-to-floor to account for the shear demand reduction along the building height. The longitudinal reinforcement ratio, computed considering tension bars only, is in the range 0.006-0.013. The beam transverse reinforcement consists of $\phi 10$ bars with $178 \mathrm{~mm}$ (7’) spacing. Spandrel beams $736.6 \mathrm{~mm}\left(2^{\prime} 5^{\prime}\right)$ height are installed at the first floor of perimetral frames. The geometry and reinforcement details are reported in Pampanin et al. [2012].

The seismic resistant columns have square sections $457.2 \mathrm{~mm}$ (18”) sides at all the building levels. Significant variations for longitudinal and transverse reinforcements can be observed along the building height, in particular at level 4 (see Fig 6). The total longitudinal reinforcement ratio in the seismic resistant columns, $\rho_{l}$, ranges between 0.012 and 0.035 . The amount of transverse reinforcement is the same for all the columns $\phi 10$ bars, $228 \mathrm{~mm}$ (9”) spaced with $135^{\circ}$ hooks. 
Furthermore, a reduced spacing, about 76mm (3"), was adopted in the plastic hinge regions at both column ends for a length of about $500 \mathrm{~mm}$.

Reinforcement details of the structural RC wall are reported in the section on the wall capacity.

At this stage, no additional variability of member strength due to geometry and details uncertainty is considered, assuming that the geometry and structural member details, clearly reported in the structural drawings, have been correctly executed and implemented.

\section{Lateral capacity of structural members}

An example of the lateral capacity of the RC members (i.e. beam, columns and joint panel) of a typical corner joint subassembly (e.g. Frame 1, floor 1, joint A1) characterized using the capacity models suggested in the guidelines is reported in Fig. 7.

The first step towards the characterization of member capacity is the moment-curvature analysis of critical cross-sections at the probable location of plastic hinges (commonly at the joint interface, unless relocation details are adopted). The beam flexural capacity is computed using the basic principles of RC cross-sections subjected to bending moment. A $20 \%$ increase of the flexural strength in negative moment regions is considered to account for the potential "flange-effect" contribution from the cast-in-situ slab reinforcement. However, it is worth mentioning that the actual draft of the NZSEE [2016c] guidelines suggests an increase about the $50 \%$. Due to the relatively adequate anchorage details of the beam longitudinal reinforcement, bent $90^{\circ}$ into the joint, no reduction of the flexural strength due to lack of bond was considered. The beam flexural capacity can be characterized by a moment-curvature analysis. In a first approximation, the yielding curvature can be well approximated with dimensionless formulae properly calibrated for different RC members by Priestley and Kowalsky [2000], see Table 2. The ultimate curvature (referred to as "probable curvature capacity" in the guidelines) can be estimated as the ratio of the confined 
concrete ultimate strain, $\varepsilon_{c u}$, and the neutral axis depth, $c$. The confined concrete ultimate strain, considering the confinement effects of transverse reinforcements, can be computed using a modified Mander et al. [1988] formulation (Table 2).

Once the key points of the moment-curvature of a structural element (beams, columns or walls) have been evaluated, either by hand with simplified approach described above, or using a more refined moment-curvature analysis, the corresponding moment-rotation curve can be derived by integrating the curvature profile (elastic and plastic) along the equivalent cantilever length and after defining a plastic hinge length. The plastic hinge length in this context is the portion of the member length over which the plastic behaviour is assumed to be concentrated and the plastic curvature is assumed to be constant. The formulations suggested in the NZSEE guidelines to compute the yield/ultimate displacement, the plastic hinge length and the member drift are reported in detail in Table 2. Fig. 7 (Beam capacity) shows the good match between the capacity curve obtained using the NZSEE guidelines approach and refined numerical analysis performed using validated computer tools (i.e. CUMBIA software, [Kowalsky and Montejo 2007]).

As depicted in Fig. 7, the flexural capacity obtained from moment-curvature analysis should be checked against other potential brittle failure mechanisms or bar buckling that may limit the exploiting of the full flexural deformation. Shear strength was calculated according to the UCSD model proposed in Kowalsky and Priestley [2000] which accounts for shear strength degradation in the plastic hinge regions due to ductility demand [Del Vecchio et al. 2017b]. An intersection between the shear capacity and the flexural curve, $\theta_{\mathrm{s}}$, denotes the onset of shear mechanism (ULS) (e.g. negative bending moment, $\mathrm{M}^{-}$, in Fig. 7). Finally, the possibility that rebar buckling could limit the ULS drift of the members (chord rotation) was checked using the formulation proposed by Berry and Eberhard [2005] (see Table 2 and Fig. 7, beam capacity $\mathrm{M}^{+}$).

The lateral capacity of RC columns is defined using the same principles adopted for beams and considering the influence of the axial load on the flexural and shear capacity. The axial load acting on the columns was computed performing a load analysis considering the seismic load combination 
according to NZS 1170.5 [2004]. The dead loads due to the weight of the RC structural members $\left(25 \mathrm{kN} / \mathrm{m}^{3}\right), \mathrm{G}$, a superimposed dead load accounting for the light-weight infill walls and other permanent interior finishing, $\mathrm{D}_{\mathrm{SDL}}=0.5 \mathrm{kN} / \mathrm{m}^{2}$, and a factored live load $\Psi_{\mathrm{E}} \mathrm{Q}$ about $0.9 \mathrm{kN} / \mathrm{m}^{2}$ ( $\Psi_{\mathrm{E}}=0.3$ for office buildings) were considered. This results in a gravity load on the joint subassembly A1 about $473 \mathrm{kN}$.

If a column flexural-shear failure was expected, the ULS drift estimated using the capacity models proposed by Elwood and Moehle [Elwood and Moehle 2005a] is used. In the case of a flexural dominated column, the ultimate drift capacity is computed accounting for longitudinal reinforcement buckling. For gravity load-dominated columns the ultimate lateral displacement capacity corresponding to the loss of the bearing load capacity is computed according to Elwood and Moehle [Elwood and Moehle 2005b].

The beam-column joint capacity in terms of joint shear strength, $V_{j h}$, is evaluated considering the concrete compressive strength, the joint geometry, the longitudinal/transverse reinforcement type and the anchorages of beam bars. The equation proposed in the NZSEE guidelines (see Table 2) is based on the Mohr's circle theory applied to the joint panel subjected to external actions transmitted by framing members [Priestley 1997], see Fig. 7. In fact, it has been demonstrated that principal tensile and compression stresses are more appropriate indicators of joint damage than the probable shear stress as they can take the variation of axial load into account [Calvi et al. 2002; CEN 2005; MI 2008; Priestley 1997; Del Vecchio et al. 2014]. The dimensionless parameter $k_{j}$ is related to the joint type or reinforcement details (see Table 2). The joint damage limit states in terms of interstorey drift is assumed in compliance with available literature studies [Magenes and Pampanin 2004] as suggested in the NZSEE [2016c] guidelines (i.e. at ULS $1.2 \% \leq \theta \leq 1.8 \%$ ). In this study the joint drift at the first cracking is set at $0.5 \%$ for exterior joints and $0.75 \%$ for interior ones. At the ULS the joint drift is assumed about $1.0 \%$ for exterior joints and $1.5 \%$ for interior ones. 
The joint core is well detailed (5 $\phi 10$ stirrups, $100 \mathrm{~mm}$ spaced, $\mathrm{A}_{\mathrm{st}}=2 \times 5 \times 3.14 \times 10^{2} / 4=785 \mathrm{~mm}^{2}$ ). However, it was not explicitly designed to achieve capacity design criteria. This may result in the joint cracking, joint shear failure and, in turn, in a reduced capacity of the subassembly limiting the seismic performance of the whole frame. It is worth mentioning that, at a first stage of the assessment, the presence of joint stirrups was neglected in order to be more conservative. Then the capacity of the building was re-assessed considering the joint stirrups by using the formulations proposed by the NZSEE [2016c] guidelines. More details can be found in Del Vecchio et al. [Ciro Del Vecchio et al. 2017].

\section{Hierarchy of strength}

The hierarchy of strength allows to compare the capacity of all the members of a joint subassembly and to establish the sequence of failures. To compare different members and failure modes a unique, consistent parameter is needed. As proposed in the procedure in [Calvi et al. 2002; Pampanin et al. 2007; Tasligedik et al. 2016], the equivalent column moment is used. The basic idea is to calculate the moment in the column, at the interface with the joint panel, corresponding to the development of specified failure (ULS in this case) mechanisms of the other members of the subassembly (i.e. beam plastic hinge, joint shear failure, etc). The mechanism associated with the lowest column moment it is likely to happen first and characterise the strength hierarchy. The likely sequence of events can thus be captured and predicted.

To convert the member strength into equivalent column moment, $\mathrm{M}_{c}$, rotational equilibrium equations of the joint sub-assembly can be used. The equations expression the capacity of all the structural members in terms of equivalent column moment are summarized in Table 3.

In order to account for the axial load variation on the exterior columns due to the seismic shaking (frame effect), the member capacity, when assessing the strength hierarchy, is reported in an Equivalent Column Moment-Axial Load (M-N) interaction diagram, or performance domain (see Fig. 8). The member's capacity should be computed varying the axial load demand in the adopted 
capacity models (see Table 2) properly converted in $\mathrm{M}_{\mathrm{c}}$. Furthermore, a representation of the seismic demand in terms $\mathrm{M}_{\mathrm{c}}-\mathrm{N}$ is needed. This can be addressed by expressing the bending moment demand as a function of the axial load variation due to the lateral sway of the frame using equilibrium considerations at frame level [Kam 2011; Pampanin et al. 2007; Tasligedik et al. 2016]. The demand can be calculated with the following equation:

$$
N_{\text {seismic }}=N_{g} \pm \alpha F=N_{g} \pm \alpha \frac{F}{F_{c}} F_{c}
$$

where $\alpha=\frac{2 \mathrm{H}_{\text {tot }}}{3 \mathrm{~L}_{\text {tot }}}(=0.8$, in this case $)$ is a coefficient that depends on the global overturning equilibrium of the frame (when neglecting, for simplicity, the contribution of the base column), and $F_{c}$ can be expressed as function of the $\mathrm{M}_{\mathrm{c}}$ using equilibrium considerations. In particular, Kam [2011] proposed $\mathrm{F}_{c}=\frac{5 \mathrm{M}_{c}}{2 \mathrm{H}}$. The ratio $\mathrm{F} / \mathrm{Fc}$ depends on the column shear distribution. For regular frames, the latter ratio can be assumed equal to 4.

The seismic demand is a straight line - and its variation appear as V-shaped curve - in the $\mathrm{M}_{\mathrm{c}}-\mathrm{N}$ performance domain resulting, for the A1 joint subassembly in Fig. 8, in axial load decrease in the push direction and axial load increase in the pull direction. The intersections of the demand and the capacity of each component provides the 'sequence of events' or mechanisms.

Table 3 also reports the calculations needed to compute the equivalent column moment and the axial load corresponding to the intersection between the demand and the capacity in the push direction of the seismic force as depicted in Fig. 8.

Once the member capacities/strength are converted into equivalent column moment, the performance domain can be drawn. Fig. 8 shows the performance domain of the external joint at the first floor (joint A1). The strength hierarchy outlines a failure sequence typical of existing beamcolumn subassemblies designed with seismic details not conforming to current seismic codes (i.e. lack of adequate amount of joint stirrups). The joint cracking and joint shear failure anticipate the development of the beam hinge both in the push and pull direction. Note that in the pull direction 
the beam shear failure for large ductility demand anticipates the joint failure. However, it is worth mentioning that this mechanism cannot appear before the beam yielding.

The strength hierarchy was performed for each sub-assembly of Frame 1, in order to have a complete view of the probable failure mechanisms. The results are summarized in Table 4 along with the equivalent column moment associated to the expected failure mechanism.

The same process was repeated by considering a $\pm 20 \%$ variation of the concrete compressive strength. This allows to account for the effects of the uncertainties in the concrete compressive strength on the failure mechanism. This may guide the designer to decide if and where address additional resources in the characterization of material properties via on-site testing.

It should be also noted that, in this specific example, in few cases the concrete strength variation affects the strength hierarchy. More specifically, for the exterior joint subassembly D1, a variation of the concrete compressive strength of $-20 \%(20 \mathrm{MPa})$ would activate a joint panel shear failure instead of a beam hinging at level 3 and 4. More details about the assessment of the flexural and shear capacity of all the structural members of Frame 1 are reported in Del Vecchio et al. [Ciro Del Vecchio et al. 2017].

\section{Lateral capacity of Frame 1}

Once the nonlinear behaviour of all the structural components is evaluated, the lateral capacity of seismic resisting systems can be assessed. In this paper, the lateral capacity of the Frame 1 is calculated considering three different failure mechanisms: Beam sideway, Column sidesway and Mixed sideway. Fig. 9 reports the force and displacement distribution on Frame 1 according to the three failure mechanisms.

The Beam-Sway mechanism represents an upper bound of the lateral load capacity and it assumes that all the beams plastic hinges have formed (yielded) at all floors and at the base columns. The base shear, $\mathrm{V}_{\mathrm{b}, 1}$, can be computed dividing the overturning moment, OTM, ${ }_{, 1}$, by the frame effective 
height, $H_{\text {eff }}$ (see Fig. 9). The effective height is herein computed using the displacement profiles suggested by NZSEE [2006] for frames with number of floors ranging between 4 and $20 . V_{\text {end,beam }}$ is the end beam shear in correspondence of the beam flexural yielding. It can be computed as $\left(\mathrm{M}_{\mathrm{b}, \text { left }}+\mathrm{M}_{\mathrm{b}, \text { right }}\right) / \mathrm{L}_{\mathrm{bay}}$, where $\mathrm{M}_{\mathrm{b}, \text { left }}$ and $\mathrm{M}_{\mathrm{b}, \text { right }}$ are the bending moments at the extremes of the end beams of a frame (in this case A1-B1 and C1-D1). The distribution of yielding moment of end beams is reported in Fig. 9. Based on equilibrium considerations, the total axial load variation at the base of the frame, $\Delta \mathrm{N}$, corresponds to the sum of the shears at the end beams. $\mathrm{M}_{\text {col, }, \mathrm{i}}$ is the flexural capacity of base columns. The flexural capacity of exterior columns (A1, D1) is computed considering the axial load variation due to the beam shear ( $\Delta \mathrm{N}$ positive or negative, depending on the load direction).

An estimation of the lateral displacement at the effective height, $\mathrm{H}_{\mathrm{eff}}$, corresponding to the assumed force distribution can be evaluated by multiplying the drift corresponding to the (first) beam yielding/ultimate capacity by $\mathrm{H}_{\text {eff. }}$ For the specific case of Frame 1, the ultimate displacement capacity is characterized by the flexure-shear failure of three beams at the bottom levels (1 and 2) when subjected to a negative bending moment $\left(\theta_{\mathrm{u}, \mathrm{beam}}=1 \%\right)$. The lateral capacity curve corresponding to the beam sidesway mechanism is depicted in Fig. 10.

The frame lateral capacity referring to the Column-Sway mechanism should be computed assuming that all the columns at the same level are yielded forming a soft-storey mechanism. This mechanism represents, in most cases - when a weak column/strong-beam design has been adopted- a lower bound of the lateral load capacity. It may involve one or more floors and it can be assumed that the mechanism with the lowest base shear is the most probable. Alternatively, the Sway Potential Index [Priestley 1997] can be computed to determine the weakest floor. In this work, for sake of simplicity, it is assumed that the mechanism involves the ground floor columns.

In the calculation of the base shear corresponding to a Column Sidesway mechanism, $\mathrm{M}_{\text {col, }}$ is the $\mathrm{i}^{\text {th }}$ column flexural capacity at the base. For sake of simplicity, the column moments associated with 
the gravity load are used for the calculations (as suggested in [Priestley et al. 2007]). The effective height is assumed equal to half of the total frame height. In the specific case of Frame 1, the lateral displacement capacity is limited by the concrete core crushing $\left(\theta_{\mathrm{u}}=3.3 \%\right)$ of corner columns (A1/D1) at level 1. In this case, because of the increasing amount of stirrups at the column's ends (i.e. $76 \mathrm{~mm}$ spacing), the buckling does not affect the column response. It is worth noting that in this case, since that the ratio of beam-to-column capacity is lower than 1 , the base shear corresponding to column sidesway is higher than the beam sidesway mechanism. This also happens if a soft-storey is assumed at upper levels. This means that a column sidesway mechanism would not be expected reflecting the good practice of the days adopted in the design of this building and already incorporating basic capacity design principles.

The Mixed-Sway mechanism represents the most refined estimation of the lateral capacity of the frame. In fact, the hierarchy of strength accounts for all the possible failure mechanisms that may significantly reduce the structural capacity, including the shear failure of joints, columns and beams. The base shear of the frame can be computed with the same formulation used for the beam sidesway mechanism, except that the beam-end shear, $\mathrm{V}_{\text {end beam, }}$ should be computed considering the strength hierarchy of the joint subassembly. A summary of the component failure mode at each floor is reported in Fig. 9 along with the related column and beam moments. In this case, the bending moment acting on the beams is calculated as the sum of the moments of the columns framing in the joint, divided by the number of beams ( 1 for exterior joints, 2 for interior) $M_{b}=$ $\sum M_{c} / n_{b}$. The actual beam moment should be calculated inverting formulations to calculate the equivalent column moment summarized in Table 3. This approximation leads, in this case, to slight underestimate the base shear in favour of a more clear illustration of the results. Evaluating the flexural capacity of base columns, $\mathrm{M}_{\mathrm{col}, \mathrm{i}}$, the axial load variation due to the frame effects has been considered. 
As outlined in Fig. 9, the lateral capacity of the mixed sidesway mechanism is limited by the joint shear failure. In turn, the lateral displacement capacity at the yielding or ultimate is computed considering the drift of the joint at the peak strength, $\theta_{\mathrm{J}, \text { peak }}=0.5 \%$, and at the beginning of strength degradation, $\theta_{\mathrm{J}, \mathrm{u}}=1 \%$, respectively. The predicted failure mechanism well reflects the observed earthquake response. However, as depicted in Fig. 3 the spandrel beam installed at the first floor prevented the joint panel shear failure leading to the top column shear failure. For sake of brevity, the influence of short columns on the lateral response of RC frames is neglected in this study. The influence of this failure mechanism on the seismic response of RC frames is properly quantified in Del Vecchio et al. [2017] by using the suggestions provided by NZSEE guidelines.

Fig. 10 outlines that the lateral capacity of the mixed sidesway mechanism, which is the most representative of the lateral capacity of Frame 1, is significantly lower than beam sidesway mechanism, due to the fact that not all the beam plastic hinges are being activated.

\section{Lateral capacity of other resisting systems}

The lateral capacity of the Frame A/D is calculated with the same procedure adopted for the Frame 1, illustrated in detail in the previous sections. The lateral capacity and the most probable mixed sidesway mechanism accounting for the strength hierarchy of the joint subassemblies are reported in Fig. 14.

In the case of Frame A/D, the strength hierarchy outlines that for most of the joint subassemblies the joint cracking anticipates the beam hinging (see Fig. 16a). This may significantly affect the lateral deformability of the resisting frame, because, after the cracking, the joints exhibit large shear deformation leading to a significant reduction of the frame lateral stiffness. To account for this phenomenon, the joint contribution to the total drift should be computed and added to the beam deformation. However, for sake of simplicity in this example the Frame A/D yielding displacement (and the initial stiffness) is computed twice. First considering the beam deformability at yielding 
$\left(\theta_{\mathrm{y}}=0.0027 \mathrm{rad}\right)$ and then considering the joint deformability at peak strength $\left(\theta_{\mathrm{y}}=0.005 \mathrm{rad}\right)$ to estimate the frame initial stiffness. In the following calculations, the capacity curve referring to the joint deformability is used, as it leads to a more conservative assessment of the seismic capacity.

\section{Lateral capacity of the wall and dual system}

The lateral capacity of the $\mathrm{C}$-wall and its interaction with the surrounding frame in Y-direction (dual system) is assessed by decoupling the $\mathrm{C}$-wall in the two $\mathrm{X}$ - and $\mathrm{Y}$ - directions. Detailed calculations, reported in Del Vecchio et al. [Ciro Del Vecchio et al. 2017] have shown that the coupling effects do not significantly affect the overall building response.

In this paper, the wall web is considered as part of a dual system (i.e. wall + frame) in the Ydirection. It is assumed that the wall flanges contributing to the building capacity in the $\mathrm{X}$ direction along with Frame A and Frame D whose capacity is independently determined according to a similar step-by-step procedure previously described for the Frame 1.

The moment-curvature capacities of the wall cross-sections at each level, accounting for the axial load variation and the different longitudinal reinforcements, need to be derived. The wall flexural strength is checked against the shear strength to detect shear failures along the wall height. In fact, flexure-shear interaction as well as shear failure prior to yielding are likely to govern the behaviour of walls.

The probable flexural strength of a shear wall at the critical sections can be computed following the procedure previously described for the columns. In general terms, the evaluation of ultimate curvature for walls can be carried out in a similar manner to that presented for columns. It is worth mentioning that a traditional section analysis approach may lead to unconservative results and overestimate the curvature/rotation/displacement demand of walls. This is because in shear dominated members, the main hypothesis of 'plane sections remain plane' might not be valid. However, while acknowledging the limitations of section analysis, it can still be a valuable 
approach to determine an upper bound of the deformation capacity of an existing wall under an ideal flexural dominated behaviour.

For example, the geometry and reinforcement details of wall web at level 1 (Y directions) are reported in Table 5 and Fig. 11 along with the schematic of the C-wall structural details.

As already reported in the characterization of the column nonlinear behaviour, the confined concrete ultimate strain can be computed using the formulation reported in Table 2. In this case it results in $\varepsilon_{c u}=0.0093$ using $\rho_{s}=0.0043$.

However, the buckling of longitudinal reinforcements should be also considered. In this case, because $\mathrm{s} / \mathrm{d}_{\mathrm{b}}=12.7>7$, according to the buckling limitation included in the guidelines, the steel in compression cannot yield. This limitation can be severe, leading to ultimate curvatures being just slightly higher than yielding curvature, i.e. very low ductility capacity. For this reason in this example the unconfined concrete ultimate strain $\varepsilon_{c u}=0.004$ is assumed as ultimate limit state for the wall curvature.

Once the confined concrete ultimate strain is known, the flexural strength can be computed using the cross-section analysis and accounting for axial load. At this stage, only gravity loads are considered. A summary of the wall flexural capacity is reported in Fig. 11.

The capacity models reported in Table 2 were considered computing the wall lateral deformation capacity. In particular, the drift at the yielding and the ultimate drift were computed using capacity models for the curvature and the plastic hinge length specifically developed for RC walls [Krolicki et al. 2011; Priestley and Kowalsky 2000; Priestley et al. 2007].

The wall shear strength was computed using a revised version of the UCSD model properly developed for RC wall considering all the possible failure mechanisms [Krolicki et al. 2011].

The lateral capacity of a structural wall as part of a structural system can be identified according to the procedure proposed by Priestley et al. [2007] and summarized in the NZSEE 
[2016c] guidelines. When assessing the flexural capacity of a structural wall, it is reasonable to assume a first mode behaviour [Priestley et al. 2007]. Indeed, in this case the moment capacity is always higher than the shear demand except at the column base, where a plastic hinge is expected to develop. Thus, the displacement profile of a cantilever wall can be reasonably assumed. The analytical pushover curve for the wall web is reported in Fig. $12 b$.

Note that in order to assess the wall capacity as part of a more complex structural system an effective height, $H_{\text {eff, }}$ about 0.67 of the total height is assumed. This assumption allows to calculate the base shear (flexural capacity divided by $H_{e f f}$ ) and the displacement capacity (wall drift previously calculated- multiplied by $H_{\text {eff }}$ ).

In this example, the nonlinear behaviour of framing members is assumed as those reported in the previous paragraphs for Frame 1. Their contribution at each floor can be computed imposing to the weaker frame member the drift at the significant points of the wall nonlinear behaviour, i.e. yielding and ultimate drift, as illustrated in Fig. 12a. This allows to compute the distribution of bending moment, shear and axial load on the frames and the corresponding actions transmitted to the wall.

The pushover curve of the dual system and the contribution of the cantilever wall and the surrounding frame are depicted in Fig. 12b. It is worth noting that, in this case study, the frame provides a substantial contribution (about the $38 \%$ ) to the total base shear. To obtain a more refined assessment of the lateral response of the dual system, the shear and flexural strength previously calculated can be now compared with a more refined estimation of the shear and bending moment demand determined accounting for the contribution of the frames at each floor.

Note that, at a later stage, the interaction with the floor system, potentially affecting the response due to displacement incompatibility considerations, might need to be checked. Generally, the cast in-situ concrete floors are flexible enough to satisfactory accommodate in-plane displacement 
without significant damage. Thus, incompatibility issues with the frame structure in terms of displacement are not expected for the case study building.

\section{Refined numerical modeling and comparison with SLaMA}

A two dimensional non-linear numerical model developed within the finite element method (FEM) software Ruaumoko [Carr 2009] was adopted to assess the capacity of lateral resisting systems. A lumped plasticity approach, concentrating RC member nonlinearities in critical members such as the sections at the end of the beams and columns and beam-column joints, was adopted (see Fig. 13). The influence of joint response on rotational capacity of framing members (with not negligible effects on the interstorey drift and frame deformability, see also Calvi et al. [2002] Pampanin et al. [2002] Del Vecchio et al. [2014, 2016]) was considered including joint rotational springs that connect the beam and column members that converge in one node of the structure. In this way, the relative rotation between beam and column is governed by the above mentioned lumped spring. Beams and columns were modelled by means of mono-dimensional elastic elements with inelastic behaviour concentrated at the edges in plastic hinge regions (Giberson model, see the Ruaumoko manual, [Carr 2009]). The proposed numerical models were extensively validated at both subassembly and frame level under static and dynamic loading [Galli 2005; Magenes and Pampanin 2004].

The nonlinear behaviour of the beam hinges was characterized using the bilinear MomentCurvature relationship and the equivalent plastic hinge length already computed in the previous section. They allow to define a "one-component Beam member" in Ruaumoko. In order to reproduce the change in strength and stiffness due to the axial load variation in the columns, a "general quadratic beam-column member" and able to modify the Moment-curvature based on the axial load-moment interaction diagram, was used. In order to have a meaningful comparison with the by-hand results of SLaMA, no hardening was considered for beam and column members. Special attention was reserved to the beam-column joints. In fact, joint rotational springs were 
adopted using an equivalent column moment-drift relationship (see Fig. 13) following the modelling method proposed by Pampanin et al. [2003]. In this example, the joint shear strength was evaluated considering the gravity load transmitted by the columns. The influence of the axial load variation was considered in the strength hierarchy, see Table 3.

Pushover analyses were conducted applying a linear force profile and neglecting P-Delta effects, in order to be consistent with the assumptions in the SLaMA assessment procedure. The floor slab was assumed rigid in the horizontal plane. The columns were assumed fully fixed at the base, thus neglecting Soil-Structure-interaction issues, in consideration of the 'competent' pile foundation-soil system of the building.

The top displacement, conventionally used to represent pushover curves, is converted to the displacement at the effective height, $\mathrm{H}_{\text {eff, }}$ resulting in the lateral capacity of the equivalent SDOF system [Priestley et al. 2007]. The pushover curves obtained from numerical analysis are compared in Fig. 14 with those derived by using the SLaMA.

Fig. $14 \mathrm{a}, \mathrm{b}$ shows the comparison between the SLaMA and the numerical model in terms of lateral capacity curve of Frame 1 and Frame A, respectively. The SLaMA curves well approximate the actual capacity curve obtained using the refined numerical model. It is deemed that the most important parameters affecting the seismic response of the structural system are the initial (secant to yielding) stiffness, the ultimate displacement and the maximum base shear. All these parameters are estimated with a satisfactory agreement. The main gap between the curves can be observed after the first yielding (first change of stiffness in the numerical curve). This is due the assumption of the SLaMA that all the structural members would have reached the yielding at the same global displacement demand, which is a clear approximation. A satisfactory agreement can be observed also comparing the SLaMa-derived plastic mechanisms with those obtained by the numerical analyses (see Fig. 15 and Fig. 17). This remarks the effectiveness of the SLaMA approach in predicting the lateral capacity curve and failure mechanism of RC frames. 
Although a good agreement can be observed for the Frame 1 and Frame A/D, significant differences can be observed for the Dual system. The maximum base shear and the ultimate displacement are accurately estimated. However, the comparison with the numerical curve reported in Fig. 14c outlines a significant gap in the initial stiffness. In order to further investigate the source of such discrepancy in Fig. 17 the plastic mechanism predicted using the strength hierarchy in the SLaMA approach is compared with that obtained from numerical analysis. The plastic mechanism predicted using the SLaMA well matches the one derived from refined numerical analysis. For this reason a good agreement in terms of maximum base shear and ultimate displacement is observed. The gap in the initial stiffness is due the assumption of the SLaMA on the lateral response of the wall. Indeed, according to the NZSEE/MBIE guidelines [2016c], it is assumed that the wall behaves as a cantilever system. Actually, the stiffness of the frames participating to the lateral response of the dual system changes the deformed shape of the wall and a contraflexure point at about $0.7 \mathrm{H}_{\mathrm{eff}}$ is observed in the numerical analysis. This leads SLaMA to underestimate the lateral stiffness of the dual system.

To obtain a more refined assessment of the wall behaviour and failure mode, the assumed distribution of shear and flexural strength can be now compared with a more refined estimation of the shear and bending moment demand determined accounting for the contribution of the frames at each floor. This may help to identify the height at the point of contraflexure, which can be used to have reliable estimation on the initial stiffness of the dual system.

\section{Torsional effects and \%NBS}

Once that the force-displacement capacity curves (pushover) of the lateral resisting systems in the two independent directions (X- and Y) were assessed (see Fig. 18), they need to be properly combined to obtain the building global response. In particular, two different situations are simulated: 
a) $2 \mathrm{D}$ response of the overall systems assuming no torsional effects

b) $3 \mathrm{D}$ response including torsion between the centre of mass and centre of strength, $\mathrm{e}_{\text {actual. }}$.

Different methods are suggested in the NZSEE [2016c] guidelines to account for the effect of torsion at building level. In this study the Method C: Absence of strength eccentricity [Paulay 2001], is adopted. This method can be applied if the strength eccentricity exceeds $2.5 \%$ of the relevant lateral dimension of the plan. It consists in reducing the lateral strength of members trying to eliminate the strength eccentricity.

In this case, for the $\mathrm{X}$ direction the strength eccentricity, $\mathrm{e}_{\mathrm{vx}}$, is zero and the building lateral capacity can be obtained summing the contribution of the two frames A and D and the two wall flanges (see Fig. 18). For the $\mathrm{Y}$ direction, the strength eccentricity can be computed as:

$$
e_{v y}=\frac{\sum V_{b} \cdot d_{m}}{\sum V_{b}}=\frac{(2082 \cdot 7.62)+(852 \cdot(-7.62))}{2082+852}=3.20 m
$$

In the Y direction there are only two lateral resisting systems: Frame 1 and the Dual System and the strength of the dual system is higher than that of Frame 1; in order to eliminate the eccentricity, the strength of the dual systems should be taken equal to the strength of the Frame 1. For this reason, the total building strength in the $\mathrm{Y}$ direction is taken as two times the strength of Frame1. The lateral capacity of the building in the two directions is reported in Fig. 19a, along with the lateral capacity in the Y direction neglecting 3D torsional effects (2D capacity).

According to Chapter 2 of the NZSEE guidelines [2016c], the building capacity is represented by Force-displacement (pushover) curves properly converted to be represented in the ADRS format (see Fig. 19b). The frame capacity in terms of acceleration can be derived dividing the base shear for the effective mass, $M_{\text {eff. }}$ Since the case study building has more than five floors, the mass participating to the higher modes could be relevant. In this case, the effective mass is assumed equal to the $80 \%$ of the tributary mass of the building. This assumption is based on the results of dynamic numerical simulations using a linear elastic model of the Frame 1, Frame A, Dual system and Wall 
flanges which outlined that the masses participating to the first mode is $78 \%, 79 \%, 65 \%, 63 \%$, respectively. The total floor mass, calculated from the seismic load analysis, is about 226 tons for each level. To be conservative, the $80 \%$ of the total mass is assumed to participate to the building first mode. The effective mass can be estimated as $\mathrm{m}_{\mathrm{eff}}=0.8 * 8 * 226=1446$ tons.

The $\%$ NBS can finally be computed as the capacity/demand ratio, or in practical terms as the ratio betweenthe seismic intensity leading to the ULS capacity of the building (capacity) and the seismic intensity corresponding to a 500 years design (demand for a newly designed building on the same site).

The ductility capacity of the frame can be estimated as $\mu_{\mathrm{C}}=\Delta_{\mathrm{u}} / \Delta_{\mathrm{y}}$ and is approximately 2.0 and 1.8 for the $\mathrm{X}$ and $\mathrm{Y}$ direction, respectively. The demand at the performance point can be derived reducing the elastic response spectrum for the damping reduction factor, $K_{\xi}=\left[7 /\left(2+\xi_{\text {sys }}\right)\right]^{0.5}$. Both $\mathrm{S}_{\mathrm{a}}(\mathrm{T})$ and $\mathrm{S}_{\mathrm{d}}(\mathrm{T})$ are multiplied for $\mathrm{K}_{\xi}$. The effective viscous damping of the system, $\xi_{\text {sys }}$, can be computed as $\xi_{\text {sys }}=\xi_{0}+\xi_{\text {hy }}+\xi_{\text {d, }}$, where $\xi_{0}=5 \%, \xi_{\text {hy }}$ is function of the structural system and the ductility demand (typical values are provided in the NZSEE guidelines), $\xi_{0}=0$ because no additional damping is provided. This result in an effective viscous damping about the $14 \%$. As depicted in Fig. $19 \mathrm{~b}$ the displacement demand is about $148 \mathrm{~mm}$ and $224 \mathrm{~mm}$ for the $\mathrm{X}$ and $\mathrm{Y}$ directions, respectively. This resulted in a \%NBS:

- X direction: $\% \mathrm{NBS}=(141 / 148) * 100=95 \%$ (seismic rating $\mathrm{A})$

- Y direction: $\%$ NBS $=(132 / 224) * 100=59 \%$ (seismic rating $\mathrm{C})$

Taking the minimum \%NBS of the two directions, and calculating the seismic rating as reported in the NZSEE [2017], it leads to a class C building. If the torsional effects and the actual eccentricity in the $\mathrm{X}$ direction were neglected and the building lateral capacity in the $\mathrm{Y}$ direction was taken as 
the 2D curve in Fig. 19, the \%NBS in that direction would result about $77 \%$, which significantly differs from the $59 \%$ determined accounting for torsional effects.

Note that as the strength eccentricity plays a key role in the assessment of the overall building performance and $\%$ NBS, more refined analysis, including the contribution of the wall to the lateral stiffness and the torsional behaviour of the building, are needed.

The step-by-step procedure described herein allows to identify the structural systems/members which limit the building seismic capacity.

In this example, the seismic performance is limited by the lateral capacity of Frame 1 in the Y direction. In particular, the joint panel extensive cracking is detrimental for the building seismic performances. This may allow to design efficient retrofit solutions targeting the improvement of the seismic capacity of weak members as discussed in Pampanin [Pampanin 2017].

This is confirmed by the comparison with the results of non-linear time history analysis (NLTH) conducted on a 3D numerical model accounting for bidirectional interaction at component level by using semi-elliptic bi-axial moment domains. The model is excited by a series of ground motions recorded at the closest station (Christchurch hospital), representing the Canterbury 2010-2011 earthquake sequence and applied in the building's main directions. More details on the modelling procedure and the full set of numerical results are available in Gentile [2017]. A focus on the NLTH response of Frame 1 is reported in Fig. 20. The comparison outlines that SLaMA is able to capture the maximum base shear (Fig. 20a) and the failure mechanism (Fig. 20b) of the weakest frame with reasonable accuracy also for existing buildings with dominant torsional effects.

This paper summarize an extensive research work aimed at validating and developing the use of the analytical method SLaMA for RC buildings. More specifically, this paper intends to provide a general overview of the applicability of the methodology in the common design practice with reference to a real case study building. More details about the seismic performance assessment of the case study building including consideration on the recorded ground motions, as well as 
sensitivity analysis to assess the effects of other variable and structural details (such as the presence of gravity columns, short columns, sprandel beams along with the variability of material properties) can be found in Del Vecchio et al. [Ciro Del Vecchio et al. 2017].

\section{Conclusions}

This paper illustrates the recent developments of the SLaMA procedure for the detailed seismic assessment of existing buildings. The methodology and the theoretical considerations made to simplify the available literature approaches are reported and discussed. The applicability and accuracy of the NZSEE/MBIE [2016c] procedure are discussed with reference to an existing RC building severely damaged during the Christchurch earthquake (2011, New Zealand). The DSA procedure is illustrated following an overall description of the step-by-step diagnostic process. The SLaMA method is implemented and discussed from component level (beams, columns, wall elements) to subassembly level (hierarchy of strength in a beam-column joint) and to system level (frame, C-Wall) assuming 2D and then incorporating a 3D behaviour.

Overall, the SLaMA method is able to well capture the inelastic mechanism and assess the seismic score and seismic rating (based on a \%NBS, New Building Standard) with reasonable accuracy when compared to the numerical non-linear pushover analyses.

The outcomes of this study can be summarized as follows:

- The analytically predicted capacity curves (corresponding to a mixed sidesway mechanism) and the related structural weaknesses, assessed by means of the strength hierarchy at the subassembly level, well match the observed earthquake damage detected on the case study building. Beam hinging and joint shear failures, clearly observed in the in-situ inspection in the aftermath of the 22 Feb 2011 Canterbury earthquake, are predicted;

- The direct comparison between SLaMA and refined numerical models outlines a satisfactory matching in terms of the pushover curves. SLaMA allows to simply and with 
satisfactory accuracy predict the lateral response of the frame, the plastic mechanism and the strength hierarchy of the structural subassemblies.

- The 2D capacity curves of the lateral resisting systems are combined to represent the building lateral response. When neglecting, in a first phase,torsional effects and actual eccentricity in the $\mathrm{Y}$ direction are neglected the building lateral capacity can be evaluated as asthe sum of the $2 \mathrm{D}$ curves. The $\% \mathrm{NBS}$, resulting from the comparison between the capacity curve and the seismic demand, is about $92 \%$ and $77 \%$ for the $\mathrm{X}$ and $\mathrm{Y}$ direction, respectively;

- The unbalanced stiffness/strength distribution in plan due to the presence of the C-shaped wall leads to significant torsional effect. The effect of torsion is evaluated with a simplified approach (Method $\mathrm{C}$ reported in the NZSEE guidelines). In this case, the \%NBS in the $\mathrm{Y}$ direction significantly reduces to $59 \%$;

- The refined numerical analyses lead to a seismic score of $98 \%$ NBS in the X direction and $65 \%$ in the Y direction. SLaMA leads to more conservative predictions $92 \%$ and $59 \%$ in the $\mathrm{X}$ and $\mathrm{Y}$ direction, respectively;

- The step-by-step SLaMA procedure allows to clearly identify the structural systems/members which limit the building seismic capacity. In this example, the seismic performance is limited by the lateral capacity of Frame 1 in the Y direction. In particular, the joint panel extensive cracking is detrimental for the building seismic performances. This may allow to design efficient retrofit solutions targeting the improvement of the seismic capacity of weak members.

\section{Acknowledgments}

This study was performed in the framework of the "SAFER Concrete Technology" and "Advancements in Engineering Guidelines and Standards" projects, funded by the New Zealand Natural Hazard Research Platform (NHRP) and of the PE 2014-2018 joint program DPC (Italian 
Department of Civil Protection) - ReLUIS (Laboratories University Network of Seismic

Engineering).

\section{References}

ASCE/SEI. [2007] Seismic rehabilitation of existing buildings. ASCE/SEI 41-06., Reston, VA, USA.

ATC. [2015] FEMA P-154: Rapid Visual Screening of Buildings for Potential Seismic Hazards: A Handbook, Redwood City, California.

ATC 50. [2012] Simplified Seismic Assessment of Detached, Single-Family, Wood-Frame Dwellings, Redwood City, California.

Berry, M. P., and Eberhard, M. O. [2005] "Practical Performance Model for Bar Buckling," Journal of Structural Engineering, Vol. 131, No.7, pp. 1060-1070.

Borzi, B., Crowley, H., and Pinho, R. [2008] "Simplified Pushover-Based Earthquake Loss Assessment ( SP-BELA ) Method for Masonry Buildings," International Journal of Architectural Heritage, Vol. 2, No.4, pp. 353-376.

Calvi, G. M., Magenes, G., and Pampanin, S. [2002] "Relevance of beam-column joint damage and collapse in RC frame assessment," Journal of Earthquake Engineering, Vol. 6, No.Special Issue 1, pp. 75-100.

Cardone, D., and Flora, A. [2017] "Multiple inelastic mechanisms analysis ( MIMA ): A simplified method for the estimation of the seismic response of RC frame buildings," Engineering Structures, Elsevier Ltd, Vol. 145, pp. 368-380.

Carr, A. [2009] "Ruaumoko 2D, Nonlinear FEM Computer Program," University of Canterbury, Christchurch, New Zealand.

CEN. [2005] "Design of structures for earthquake resistance - Part 3: Assessment and reofitting of buildings" EN-1998-3, Eurocode 8., European Committee for Standardization, Brussell.

Elwood, K. J., and Moehle, J. P. [2005a] "Drift Capacity of Reinforced Concrete Columns with Light Transverse Reinforcement," Earthquake Spectra, Vol. 21, No.1, pp. 71-89.

Elwood, K. J., and Moehle, J. P. [2005b] “Axial capacity model for shear-damaged columns," ACI Structural Journal, Vol. 102, No.4, pp. 578-587.

Galli, M. [2005] "EVALUATION OF THE SEISMIC RESPONSE OF EXISTING R.C. FRAME BUILDINGS WITH MASONRY INFILLS,” IUSS, Pavia.

Kam, W. Y. [2011] "Selective Weakening and post-tensioning for the seismic retrofit of non-ductile RC frames," University of Canterbury.

Kam, W. Y., Pampanin, S., and Elwood, K. [2011] "Seismic performance of reinforced concrete buildings in the 22 February Christchurch (Lyttelton) earthquake," Bulletin of the New Zealand Society for Earthquake Engineering, Vol. 44, No.4, pp. 239-278.

Kowalsky, M. J., and Montejo, L. A. [2007] CUMBIA-Set of codes for the analysis of reinforced concrete members, Raleigh, NC, USA.

Kowalsky, M. J., and Priestley, M. J. N. [2000] "Improved Analytical Model for Shear Strength of Circular Reinforced Concrete Columns in Seismic Regions d i," ACI Structural Journal, No.97, pp. 388-396. 
Krolicki, J., Maffei, J., and Calvi, G. M. [2011] "Shear Strength of Reinforced Concrete Walls Subjected to Cyclic Loading," Journal of Earthquake Engineering, Vol. 15, No.sup1, pp. 3071.

Landi, L., Tardini, A., Diotallevi, P. P., Landi, L., Tardini, A., and Paolo, P. [2016] "A Procedure for the Displacement-Based Seismic Assessment of Infilled RC Frames," Journal of Earthquake Engineering, Vol. 20, No.7, pp. 1077-1103.

Leon, R. T., Yuen Kam, W., and Pampanin, S. [2014] "Performance of beam-column joints in the 2010-2012 Christchurch earthquakes," ACI Special Pubblication, Vol. SP-296-3.

Ligabue, V., Pampanin, S., and Savoia, M. [2017] "Seismic performance of alternative riskreduction retrofit strategies to support decision making," Bulletin of Earthquake Engineering, Springer Netherlands, pp. 1-30.

Del Vecchio, C., Gentile, R., and Pampanin, S. [2017] The Simple Lateral Mechanism Analysis (SLaMA) for the seismic performance assessment of a case study building damaged in the 2011 Christchurch earthquake, UC report 2016-02, Christchurch, New Zealand.

Del Vecchio, C., Di Ludovico, M., Balsamo, A., Prota, A., Manfredi, G., and Dolce, M. [2014] "Experimental investigation of exterior RC beam-column joints retrofitted with FRP systems," Journal of Composites for Construction, Vol. 18, No.4.

Del Vecchio, C., Di Ludovico, M., Pampanin, S., and Prota, A. [2018] "Repair costs of existing RC buildings damaged by the L 'Aquila earthquake and comparison with FEMA P-58 predictions," Earthquake Spectra, No.(online publishing).

Del Vecchio, C., Di Ludovico, M., Prota, A., and Manfredi, G. [2016] "Modelling beam-column joints and FRP strengthening in the seismic performance assessment of RC existing frames," Composite Structures, Vol. 142, pp. 107-116.

Del Vecchio, C., Del Zoppo, M., Di Ludovico, M., Verderame, G. M., and Prota, A. [2017] "Comparison of available shear strength models for non-conforming reinforced concrete columns," Engineering Structures, Vol. 148, No.1, pp. 312-327.

Di Ludovico, M., Prota, A., Moroni, C., Manfredi, G., and Dolce, M. [2017a] "Reconstruction process of damaged residential buildings outside the historical centres after L'Aquila earthquake - Part II: Heavy Reconstruction,” Bulletin of Earthquake Engineering, Vol. 15, No.2, pp. 693-729.

Di Ludovico, M., Prota, A., Moroni, C., Manfredi, G., and Dolce, M. [2017b] "Reconstruction process of damaged residential buildings outside the historical centres after L'Aquila earthquake - Part I: Light Reconstruction,” Bulletin of Earthquake Engineering, Vol. 15, No.2, pp. 667-692.

Magenes, G., and Pampanin, S. [2004] "Seismic Response of Gravity-Load Design Frame with Masonry Infills," 13 th World Conference on Earthquake Engineering, Vancuver, Canada.

Mander, J. B., Priestley, M. J. N., and Park, R. [1988] "Theoretical Stress-Strain Model for Confined Concrete," ASCE Journal of Structural Engineering, Vol. 114, No.8, p. 1804.

MI. [2008] D.M. 14 Gennaio 2008 (D.M. 2008). Technical codes for structures (in Italian), Rome, Italy.

MOW. [1968] Ministry of Works, “Code of Practice, Design of Public Buildings, ” Office of Chief Structural Engineer, New Zealand. 
MOW. [1976] Ministry of Works and Development New Zealand: "Code of Practice for Seismic Design Public Buildings, ” Wellington, New Zealand.

NZS 1170.5. [2004] Structural design actions, Part 5: earthquake actions-New Zealand, Standards New Zealand, New Zealand.

NZS 3101. [2006] Concrete Structures Standard, New Zeland.

NZSEE. [2006] Assessment and Improvement of the Structural Performance of Buildings in Earthquakes, New Zealand.

NZSEE/MBIE. [2016a] The Seismic Assessment of Existing Buildings Technical Guidelines for Engineering Assessments. Part A : Assessment Objectives and Principles, New Zealand.

NZSEE/MBIE. [2016b] The Seismic Assessment of Existing Buildings Technical Guidelines for Engineering Assessments. Part B - Initial Seismic Assessment, New Zealand.

NZSEE/MBIE. [2016c] The Seismic Assessment of Existing Buildings: Technical Guidelines for Engineering Assessments. Part C - Detailed Seismic Assessment, New Zealand.

Pampanin, S. [2017] "Towards the practical implementation of performance-based assessment and retrofit strategies for RC buildings," SMAR2017- Fourth conference on Smart Monitoring, Assessment and Rehabilitation of Structures, Zurich, Switzerland, p. keynote lecture.

Pampanin, S., Bolognini, D., and Pavese, A. [2007] "Performance-Based Seismic Retrofit Strategy for Existing Reinforced Concrete Frame Systems Using Fiber-Reinforced Polymer Composites," Journal of Composites for Construction, Vol. 11, No.2, pp. 211-226.

Pampanin, S., Calvi, G. M., and Moratti, M. [2002] "Seismic behaviour of R.C. beam-column joints designed for gravity loads," 12th European Conference on Earthquake Engineering, pp. 1-10.

Pampanin, S., Kam, W. Y., Akguzel, U., Tasligedik, A. S., and Quintana Gallo, P. I. [2012] Seismic Performance of Reinforced Concrete Buildings in the Christchurch CBD in 22 February 2011 Earthquake Part II : Damage Observation, Christchurch, New Zealand.

Pampanin, S., Magenes, G., and Carr, A. [2003] "Modelling of Shear Hinge Mechanism in Poorly Detailed RC Beam-Column Joints," fib 2003 Symposium “Concrete Str. in Seism. Reg.”, May 2003. Paper $n .171$.

Park, R. [1997] "A static force-based procedure for the seismic assessment of existing reinforced concrete moment resisting frames," Bulletin of the New Zealand National Society for Earthquake Engineering, Vol. 30, No.3, pp. 213-226.

Paulay, T. [2001] "Some design principles relevant to torsional phenomena in ductile buildings," Journal of Earthquake Engineering, Vol. 2469, No.March.

Paulay, T., and Priestley, M. J. N. [1992] Seismic design of Reinforced Concrete and masonry buildings, John Wiley \& Sons, Inc., U.S.A.

Priestley, M. J. N. [1995] "Displacement-Based Seismic Assessment of Existing Reinforced Concrete Buildings," Pacific Conference on Earthquake Engineering, PCEE, pp. 256-272.

Priestley, M. J. N. [1997] "Displacement-based seismic assessment of Reinforced Concrete buildings," Journal of Earthquake Engineering, Vol. 1, No.1, pp. 157-192.

Priestley, M. J. N., and Calvi, G. M. [1991] "Towards a Capacity-desing assessment procedure for reinforced concrete frames," Earthquake Spectra. 
Priestley, M. J. N., Calvi, G. M., and Kowalsky, M. J. [2007] Displacement-Based Seismic Desing of Structures, Pavia, Italy.

Priestley, M. J. N., and Kowalsky, M. J. [2000] "Direct-displacement based design of concrete buildings," Bulletin of the New Zealand Society for Earthquake Engineering, Vol. 33, No.4, pp. $421-444$.

Priestley, M. J. N., Seible, F., and Calvi, G. M. [1996] Seismic design and retrofit of bridges, John Wiley \& Sons, Inc., New York.

Tasligedik, A. S., Akguzel, U., Kam, W. Y., and Pampanin, S. [2016] "Strength Hierarchy at Reinforced Concrete Beam- Column Joints and Global Capacity Strength Hierarchy at Reinforced Concrete Beam-Column Joints and Global Capacity," Journal of Earthquake Engineering, Taylor \& Francis, Vol. 00, No.00, pp. 1-34.

\section{List of Tables}

TABLE 1 Summary of probable material properties.

TABLE 2 Capacity model used in the characterisation of the members.

TABLE 3 Hierarchy of strength calculations for corner joint A1, Frame 1-Floor 1.

TABLE 4 Strength hierarchy summary for Frame 1.

TABLE 5 Wall-web details.

\section{List of Figures}

FIGURE 1 Flow-Chart of Performance Evaluation of RC Structures: from local (materialcomponent) to Global (system) level.

FIGURE 2 Structural configuration: plan and frontal views.

FIGURE 3 Photos showing the observed damages to the building.

FIGURE 4 Material strength stated in structural drawings [Pampanin et al. 2012].

FIGURE 5 Example of beam reinforcement details in the Longitudinal Frame 1.

FIGURE 6 Elevation scheme of column reinforcements in Frame 1, A and D.

FIGURE 7 Example of evaluation of member capacity in a beam-column joint subassembly (corner joint A1, Frame 1-Floor 1).

FIGURE 8 Strength hierarchy for the exterior joint A1 at level 1.

FIGURE 9 Force and displacement distribution of Frame 1: (a) Beam sidesway; (b) Column sidesway; (c) Mixed sidesway.

FIGURE 10 Lateral capacity curves of Frame 1.

FIGURE $11 \mathrm{C}$-wall reinforcement detail and moment-curvature capacity of wall web at the ground floor.

FIGURE 12 Lateral capacity of the dual system: (a) plastic mechanism assumed for the calculations; (b) pushover curve.

FIGURE 13 Modelling strategy (after Pampanin et al. [2003]).

FIGURE 14 Comparison of SLaMA vs Numerical capacity curves for Frame 1, Frame A, dual system and wall flange.

FIGURE 15 Frame 1 plastic mechanism: (a) SLaMA; (b) numerical pushover.

FIGURE 16 Frame A plastic mechanism: (a) SLaMA; (b) numerical pushover.

FIGURE 17 Dual system plastic mechanism: (a) SLaMA; (b) numerical pushover.

FIGURE 18 Lateral capacity of resisting systems in the (a) y direction and (b) $x$ direction.

FIGURE 19 (a) Lateral capacity of resisting systems in the two directions and (b) Demand vs. Capacity in the ADRS format for both directions with torsion.

FIGURE 20 Frame 1 NLTH response: (a) base shear vs displacement at the effective height; (b) failure mechanism. 
TABLE 1 Summary of probable material properties.

Properties

\begin{tabular}{c|ll}
\multicolumn{1}{c}{ Materials } & \multicolumn{1}{c}{ Properties } & \multicolumn{1}{c}{ Values } \\
\hline \multicolumn{1}{c}{ Concrete } & Compressive Strength $\left(f_{c}^{\prime}\right)(\mathrm{MPa})$ & $17.2 * 1.5=25.8$ \\
& Tensile Strength $\left(f_{c t}\right)(\mathrm{MPa})$ & 1.83 \\
& Elastic Modulus $\left(E_{c}\right)(\mathrm{MPa})$ & 23763 \\
& Ultimate compressive Strain $\left(\varepsilon_{c u}\right)$ & 0.004 for unconfined \\
& & concrete \\
\multirow{4}{*}{ Reinforcing Steel } & Yield Strength $\left(f_{s y}\right)(\mathrm{MPa})$ & $275^{*} 1.08=300$ \\
& Elastic Modulus $\left(E_{s}\right)(\mathrm{MPa})$ & 200000 \\
& Yield Strain $\left(\varepsilon_{y}\right)$ & 0.0015 computed as $\mathrm{f}_{\mathrm{sy}} / \mathrm{E}_{\mathrm{s}}$ \\
& Ultimate Strength $\left(f_{s u}\right)(\mathrm{MPa})$ & $1.25 * 300=375$ \\
& Ultimate Strain $\left(\varepsilon_{s u}\right)$ & 0.15
\end{tabular}


TABLE 2 Capacity model used in the characterisation of the members.

\begin{tabular}{|c|c|}
\hline $\begin{array}{l}\text { Yielding curvature } \\
\text { [Priestley and Kowalsky 2000] }\end{array}$ & $C=\left\{\begin{array}{c}2.0 \text { for RC beams } \\
1.7 \text { for RC flanged beams } \\
2.12 \text { for RC columns } \\
2.0 \text { for RC walls }\end{array}\right.$ \\
\hline $\begin{array}{l}\text { Ultimate curvature } \\
\text { [Priestley et al. 2007] }\end{array}$ & $\begin{array}{c}c_{\text {prob }} \text { is the neutral axis depth at probable } \\
\text { capacity (ULS) }\end{array}$ \\
\hline $\begin{array}{l}\text { Confined concrete ultimate strain } \\
\text { [Mander et al. 1988] }\end{array}$ & $\begin{array}{ll}\varepsilon_{c, \text { max }}=0.004+\frac{1.4 \rho_{s t} f_{y h} \varepsilon_{s}}{f_{c c}^{\prime}} & \begin{array}{l}\rho_{s t, b}=1.5 A_{v} / b_{c} s \quad \text { for beams } \\
\rho_{s t, c}=\left(A_{v x} / d_{c} s\right)+\left(A_{v y} / b_{c} s\right) \text { for columns }\end{array}\end{array}$ \\
\hline $\begin{array}{l}\text { Member drift } \\
\text { (or chord rotation) }\end{array}$ & $\begin{array}{l}L_{v}=l_{b}^{\prime} \quad \text { for beams (see Fig. 7) } \\
L_{v}=L_{c} \text { for columns (see Fig. 7) }\end{array}$ \\
\hline $\begin{array}{l}\text { Yield displacement } \\
\text { Ultimate displacement } \\
\text { [Priestley et al. 2007] }\end{array}$ & $\Delta_{u}=\Delta_{y}+\left(\phi_{u}-\phi_{y}\right) L_{p}\left(L-0.5 L_{p}\right)$ \\
\hline $\begin{array}{l}\text { Plastic hinge length } \\
\text { [Priestley et al. 2007] }\end{array}$ & $\begin{array}{c}L_{p}=k L_{c}+0.1 l_{w}+L_{s p} \\
\mathrm{RC} \text { walls }\end{array}$ \\
\hline $\begin{array}{l}\text { Drift at bar buckling } \\
\text { [Berry and Eberhard 2005] }\end{array}$ & $b=\frac{3.25\left(1+k_{e_{-} b b} \rho_{e f f} \frac{d_{b}}{D}\right)\left(1-\frac{P}{A_{g} f_{c}^{\prime}}\right)\left(1+\frac{L_{c}}{10 D}\right)}{100}$ \\
\hline $\begin{array}{l}\text { Probable shear strength for } \\
\text { beams and columns [Kowalsky } \\
\text { and Priestley 2000] }\end{array}$ & $0.85\left(\alpha \beta \gamma \sqrt{f_{c}^{\prime}} b_{v}\right.$ \\
\hline $\begin{array}{l}\text { Probable shear strength for shear } \\
\text { walls [Krolicki et al. 2011] }\end{array}$ & $V_{p}=0.85\left(\alpha_{p} \beta \gamma_{p} \sqrt{f_{c}^{\prime}} b_{w} c\right.$ \\
\hline Joint shear strength & $V_{j h}=0.85 b_{j} \mathrm{~h} \sqrt{p_{t}^{2}}$ \\
\hline Princ. tensile stress strength & $p_{t}=k_{j} \sqrt{f_{c}^{\prime}} \quad k_{j}=\left\{\begin{array}{c}0.8 \text { for interior joints } \\
0.4 \text { for ext. joints, beam deformed bars anchored } 90^{\circ} \text { in the joint } \\
0.3 \text { for joint first cracking or ext. joints } \\
0.2 \text { for ext. joints, beam plain round bars anchored with hooks }\end{array}\right.$ \\
\hline Joint panel normal stresses & $f_{h}=\frac{A_{s t} f_{y}}{b_{j} h_{b}}$ \\
\hline $\begin{array}{l}\text { Ultimate displacement for } \\
\text { flexure-shear failure [Elwood and } \\
\text { Moehle 2005a] }\end{array}$ & $\Delta_{s}=L_{c}\left(0.03+4 \rho_{s}-0.024 \frac{v}{\sqrt{f_{c}^{\prime}}}-0.025 \frac{P}{A_{g} f_{c}^{\prime}}\right) \geq 0.01 L_{c}$ \\
\hline $\begin{array}{l}\text { Ultimate drift for gravity } \\
\text { columns } \\
\text { [Elwood and Moehle 2005b] }\end{array}$ & $\left.\frac{1+\tan ^{2} 65^{\circ}}{+P\left(\frac{s}{A_{s t} f_{y t} d_{c} \tan 65^{\circ}}\right)}\right)$ \\
\hline
\end{tabular}

where: $\varepsilon_{y}$ is the steel yield stress; h depth of the member; $\phi_{y}, \phi_{u}$ first yield and ultimate curvature of the member; $\rho_{s t}, f_{y h}, \varepsilon_{s}$ volumetric ratio, yield stress and ultimate strain of transverse reinforcement; $A_{v x}, A_{v y}$ area of the shear reinforcement in the two principal directions of the cross section; $d_{c}, b_{c}$ effective dimensions of the section ( $80 \%$ of the total); $\theta$ member drift; $L_{v}$ shear span; $\Delta_{y}, \Delta_{u}$ yield and ultimate displacements; $L_{p}$ equivalent plastic hinge length; $k$ hardening coefficient; $L_{s p}$ strain penetration length; $k_{e_{-} b b}$ transverse reinforcement coefficient; $\rho_{\text {eff }}$ effective confinement ratio; $d_{b}$ average diameter of longitudinal reinforcement; $D$ section effective depth; $P$ member axial load; $A_{g}$ gross section area; $f_{c}^{\prime}$ unconfined concrete strength; $L_{c}$ column shear span; $\alpha, \beta, \gamma$ aspect ratio, dowel effect and shear strength degradation factors $\left(\alpha_{p}, \beta, \gamma_{p}\right.$ analogous for walls); $b_{w}$ width of section web; $d$ effective depth of section; $N$ axial load; $f_{y t}$ probable yield strength of the transverse reinforcement; $s$ stirrup spacing; $\theta_{c r}$ diagonal crack angle; $h_{c r}$ diagonal crack vertical height; $b_{j}$ effective width of the joint; $p_{t}$ principal tensile stress in joint panel; $f_{v}, f_{h}$ vertical and horizontal normal stresses on joint; $N_{g}$ gravity axial load; $A_{s t}$ transverse reinforcement area; $v$ shear stress ratio. 
TABLE 3 Hierarchy of strength calculations for corner joint A1, Frame 1-Floor 1.

\begin{tabular}{|c|c|c|c|}
\hline Mechanism & Eq. Col. Moment & $\mathbf{N}=\mathbf{N}_{\mathrm{g}} \pm \alpha \mathrm{F}[\mathrm{kN}]$ & Eq. Col. Moment \\
\hline Joint cracking & $M_{c}=\frac{V_{j h}(N) l_{c}^{\prime}}{\frac{l_{c} l_{b}^{\prime}}{l_{b} j_{d}}-1}$ & +174 & $M_{c}=\frac{335 * 1.16}{\frac{3.05 * 3.17}{3.4 * 0.9 * 0.70}-1}=111$ \\
\hline Joint failure & $M_{c}=\frac{V_{j h}(N) l_{c}^{\prime}}{\frac{l_{c} l_{b}^{\prime}}{l_{b} j d}-1}$ & +118 & $M_{c}=\frac{409 * 1.16}{\frac{3.05 * 3.17}{3.4 * 0.9 * 0.70}-1}=135$ \\
\hline Beam Flexure & $=\frac{M_{Y, b}}{2}$ & 0 & $M_{c}=\frac{403}{2}=201.5$ \\
\hline Beam Shear & $M_{c}=V_{R e s, b} l_{b} \frac{l_{c}^{\prime}}{l_{c}}$ & 0 & $M_{c}=262 * 3.4 \frac{1.16}{3.05}=339$ \\
\hline Column flex. & $M_{c}=M_{Y, c}$ & -430 & $M_{c}=370$ \\
\hline Column Shear & $M_{c}=l_{c}^{\prime} V_{R e s, c}$ & computed for $\mathrm{N}=0$ & $M_{c}=1.16 * 613=711$ \\
\hline
\end{tabular}


TABLE 4 Strength hierarchy summary for Frame 1.

Joint Level Hierarchy Hierarchy Hierarchy $M_{c}$

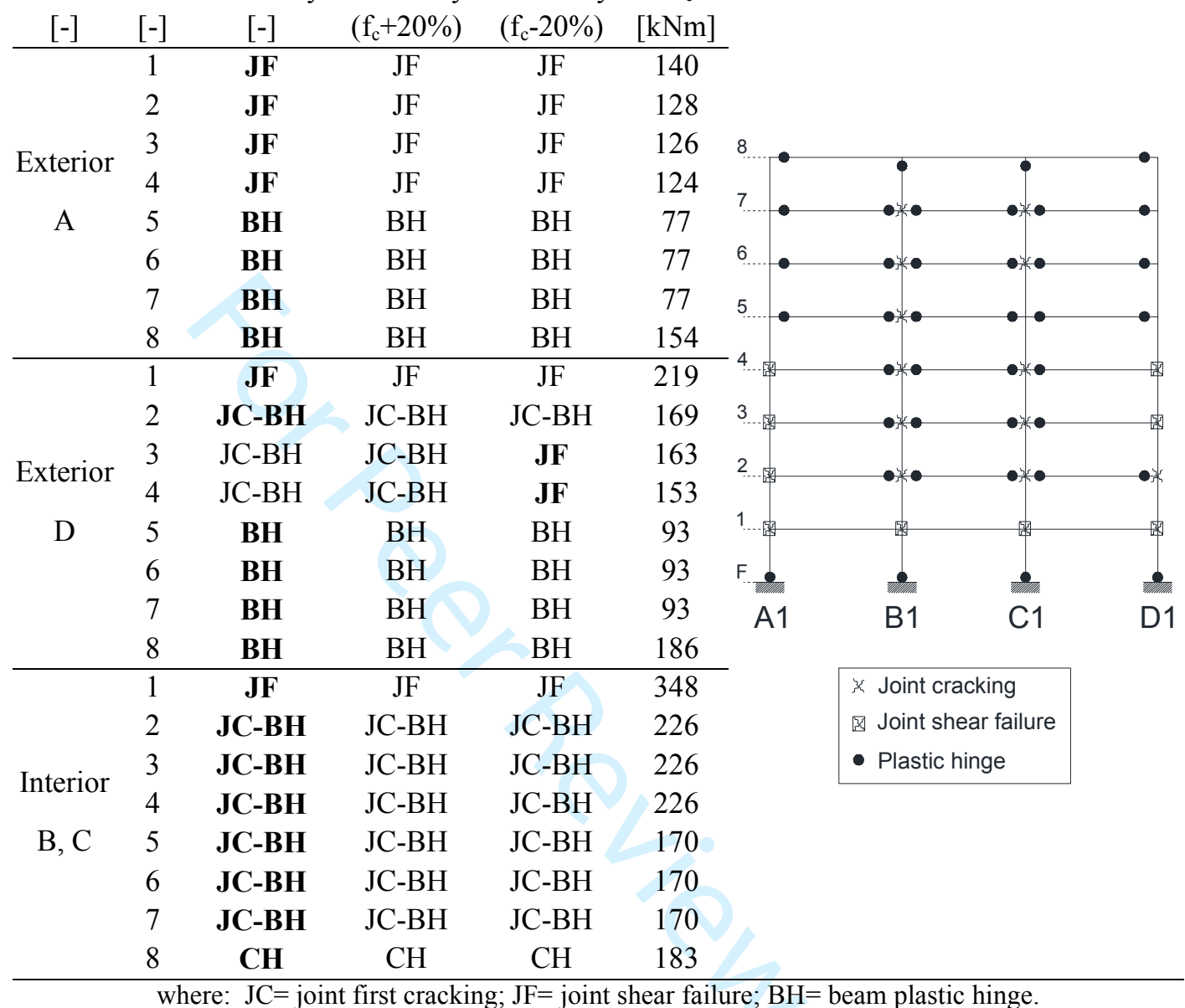


1

2

3

4

5

6

7

8

9

10

11

12

13

14

15

16

17

18

19

20

21

22

23

24

25

26

27

28

29

30

31

32

33

34

35

36

37

38

39

40

41

42

43

44

45

46

47

48

49

50

51

52

53

54

55

56

57

58

59

60

TABLE 5 Wall-web details.

\begin{tabular}{cccc|cccc}
\hline \multicolumn{7}{c}{ Wall web (Y direction) } \\
\hline Wall width & $\mathrm{b}$ & {$[\mathrm{mm}]$} & 203.2 & Stirrups diameter & $\phi_{\text {stirr }}$ & {$[\mathrm{mm}]$} & 10 \\
Wall length & $1_{\mathrm{w}}$ & {$[\mathrm{mm}]$} & 6100 & Stirrups spacing & $\mathrm{S}_{\text {stirr }}$ & {$[\mathrm{mm}]$} & 254 \\
Longit. bar cover & $\mathrm{clb}$ & {$[\mathrm{mm}]$} & 38.1 & Number of legs & $\mathrm{n}_{\mathrm{lx}}=\mathrm{n}_{\mathrm{ly}}$ & {$[-]$} & 2 \\
Total height & $\mathrm{H}$ & {$[\mathrm{mm}]$} & 24400 & Longit. bar diameter & $d_{b}$ & {$[\mathrm{~mm}]$} & 20 \\
Axial load & $\mathrm{N}_{\mathrm{g}}$ & {$[\mathrm{kN}]$} & 2624 & Axial load ratio & $\mathrm{v}=\mathrm{N}_{\mathrm{g}} /\left(\mathrm{A}_{\mathrm{g}} * \mathrm{f}_{\mathrm{c}}\right.$ ) & {$[-]$} & 0.07 \\
\hline
\end{tabular}



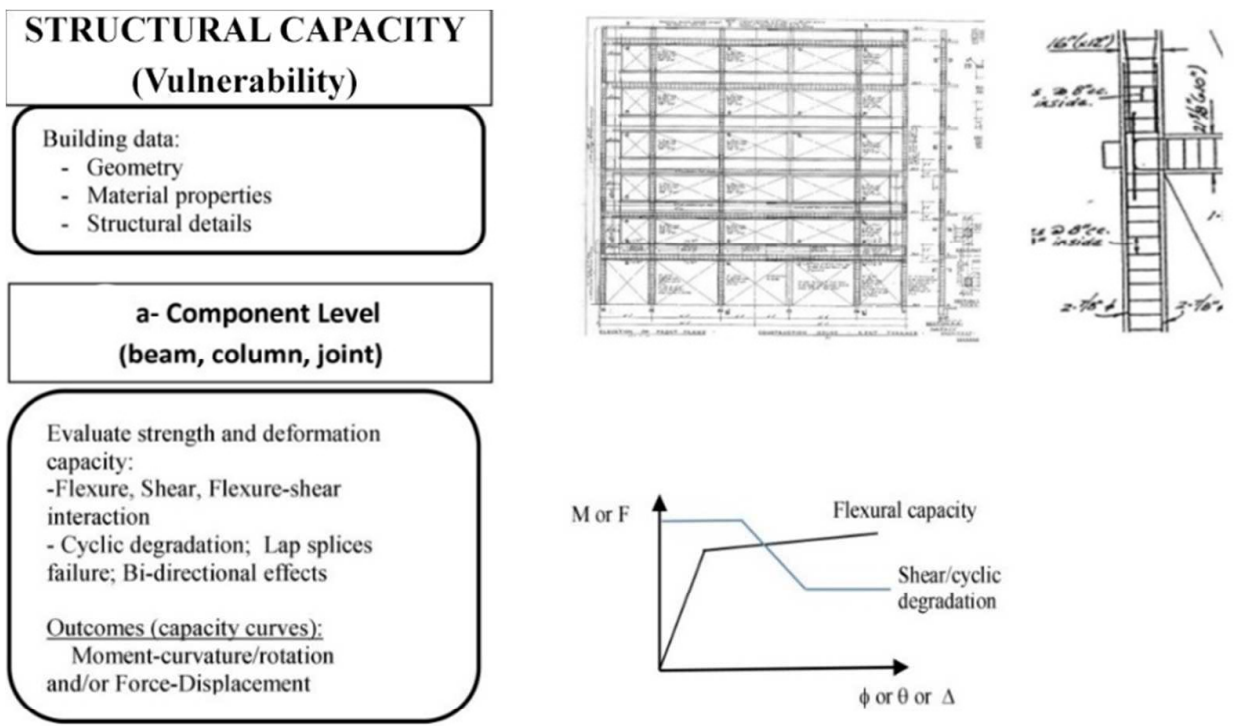

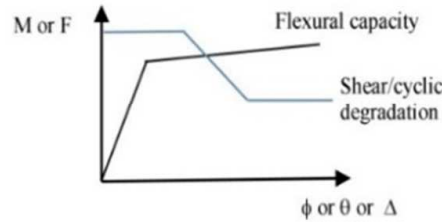

\section{1}
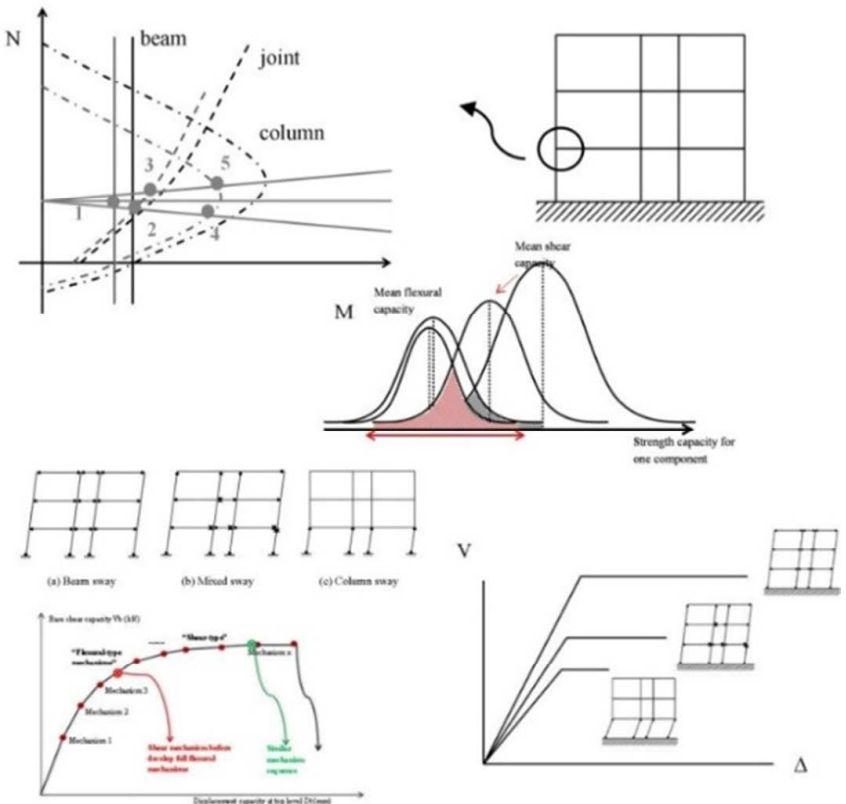

s.
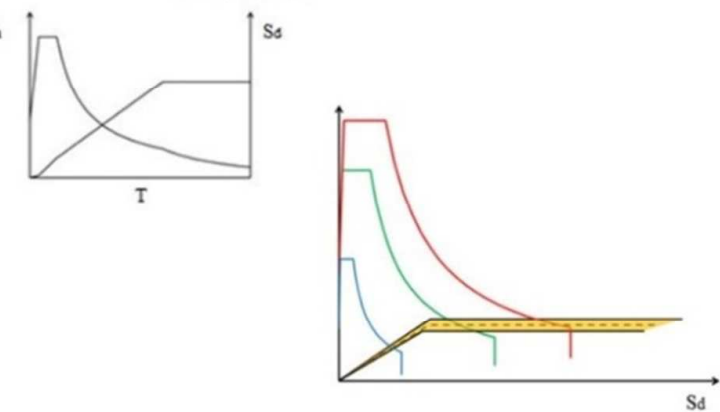

FIGURE 1 Flow-Chart of Performance Evaluation of RC Structures: from local (materialcomponent) to Global (system) level. 


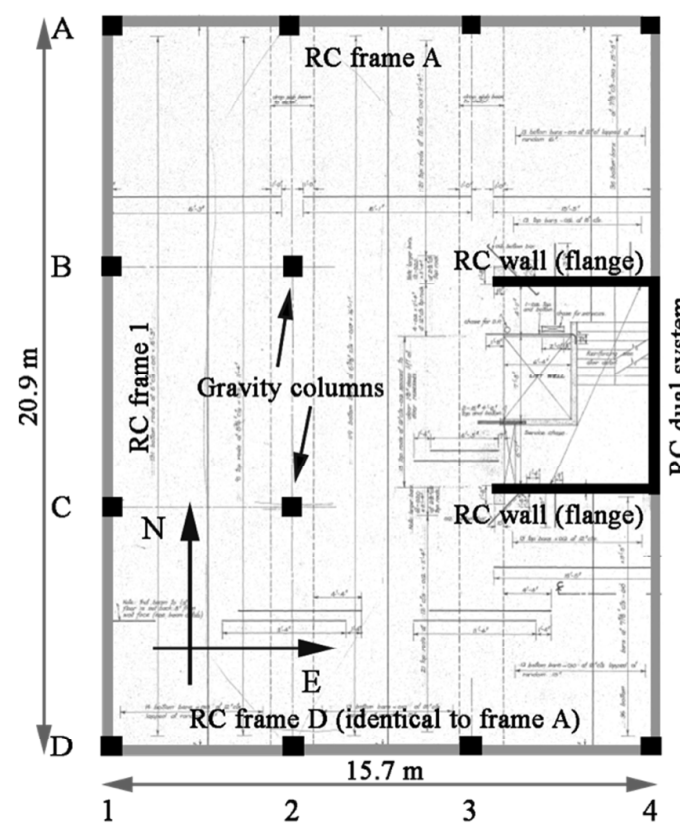

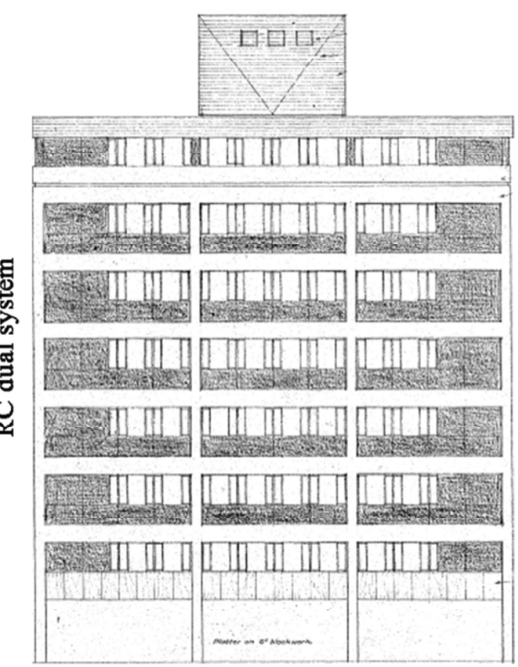

West view: Frame 1

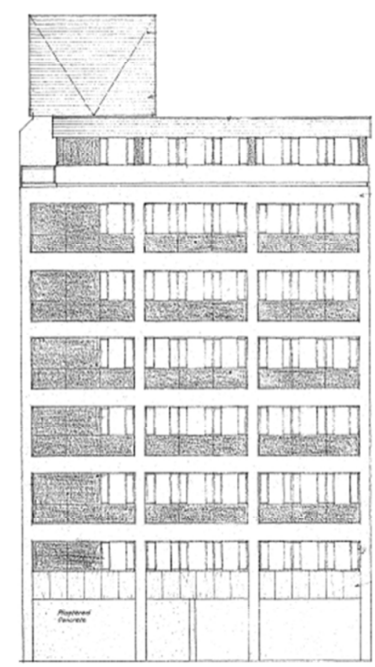

North view: Frame A

FIGURE 2 Structural configuration: plan and frontal views. 


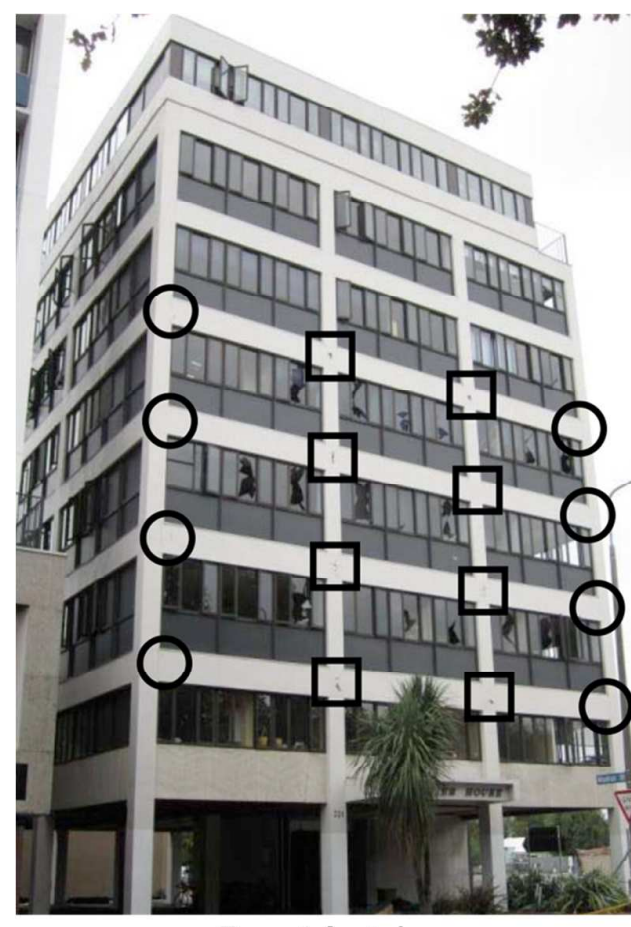

Frame 1 front view
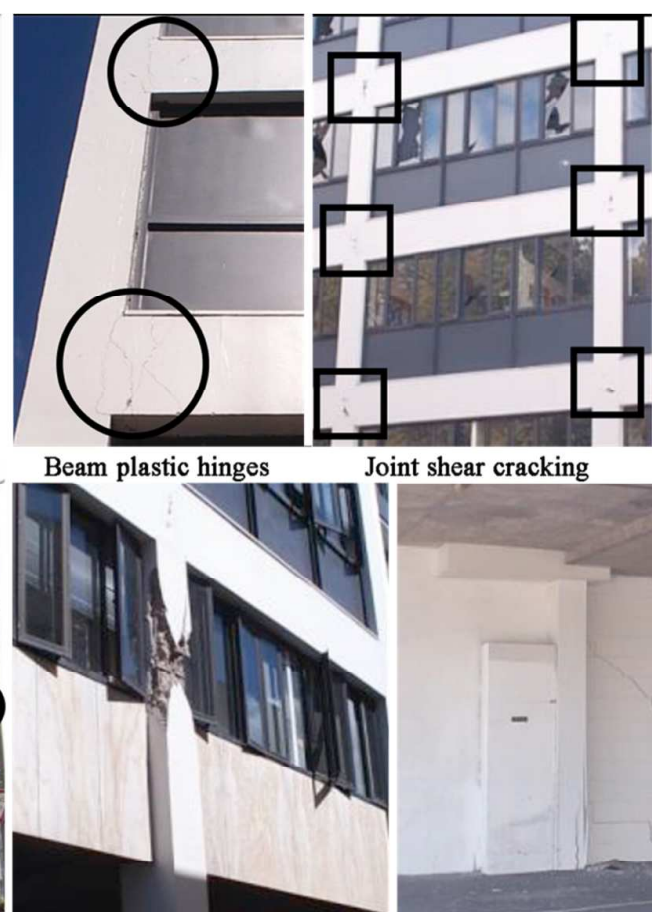

Short column (Frame A)

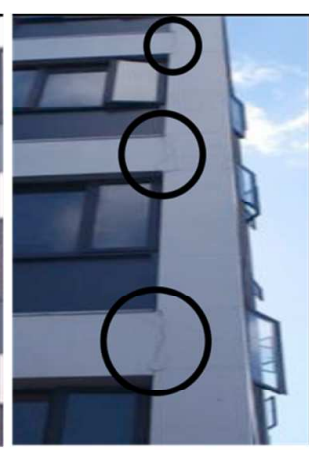

Beam plastic hinges

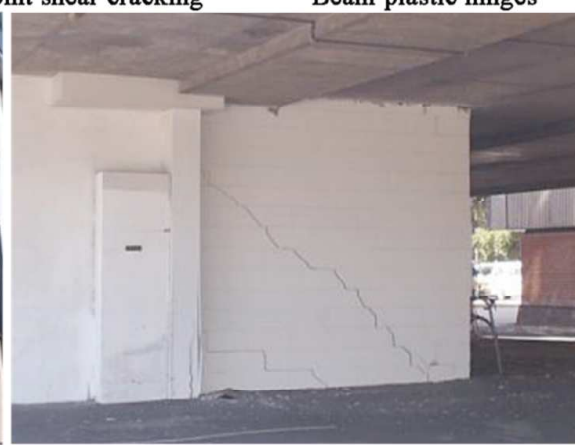

Non-structural brick wall shear crack

FIGURE 3 Photos showing the observed damages to the building. 
FIGURE 4 Material strength stated in structural drawings [Pampanin et al. 2012].

NZS 1693 deformed bars of structural grade

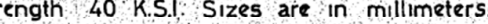
$016=16$ millimeters.) All columns and beam ties and stirrups in smooth round of same grade. All laps 32 diameters except as otherwise stated. minimum crushing strength at 28 days on standard $12^{\prime \prime} \times 6^{\prime}$ dia cylinder standard are of $3,500 \mathrm{lb} / \mathrm{sq}$ in to top face of $2 \mathrm{nd}$

REINFORCING STEEL

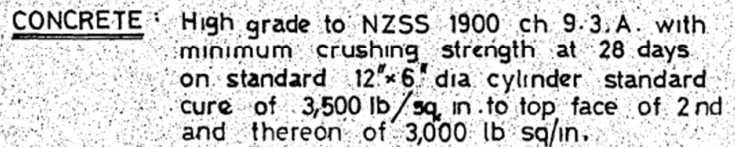




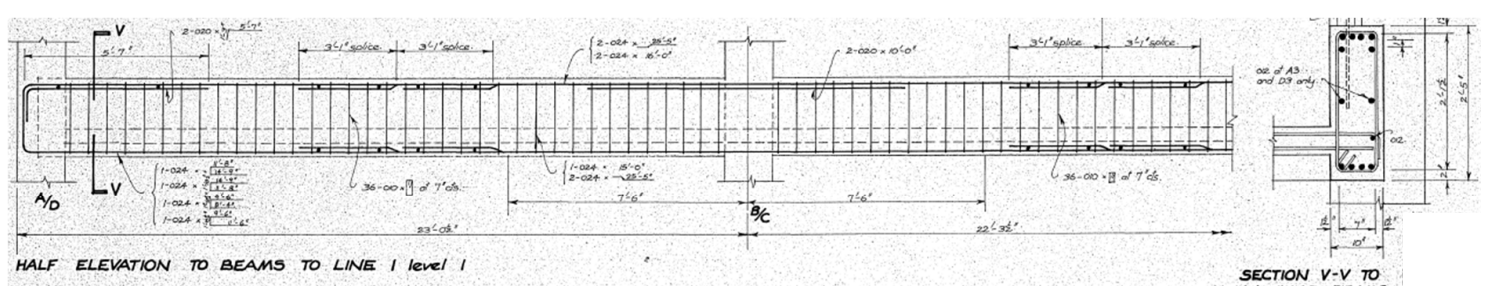

FIGURE 5 Example of beam reinforcement details in the Longitudinal Frame 1. 

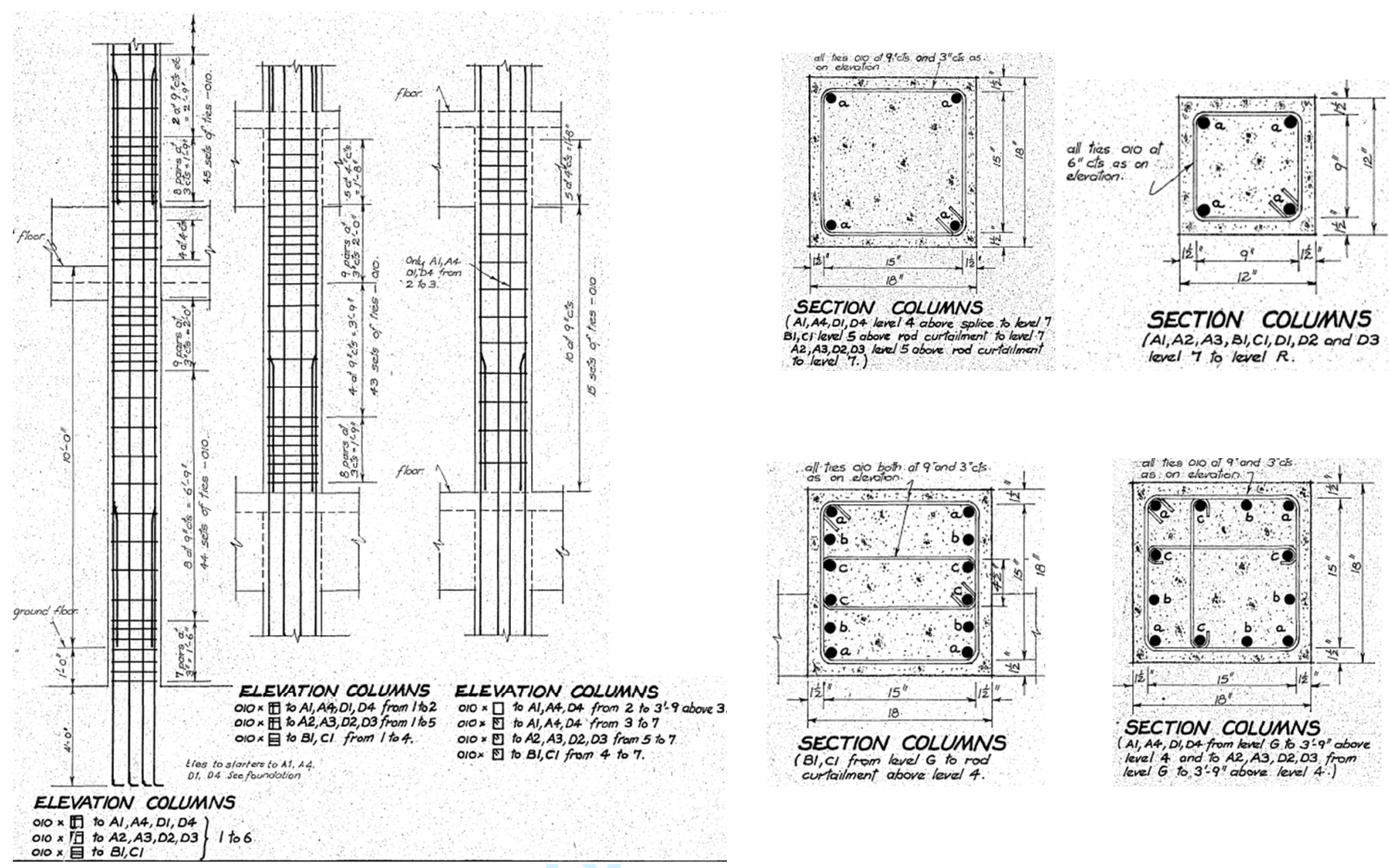

FIGURE 6 Elevation scheme of column reinforcements in Frame 1, A and D.
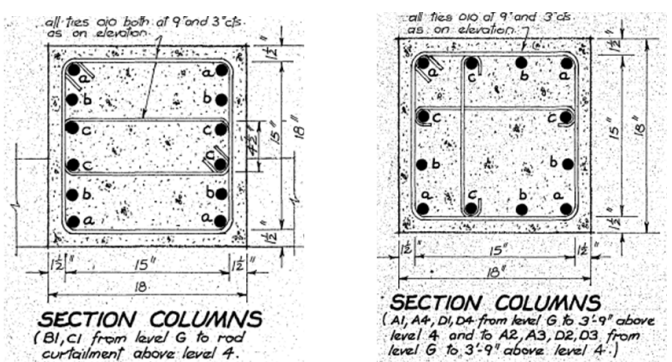


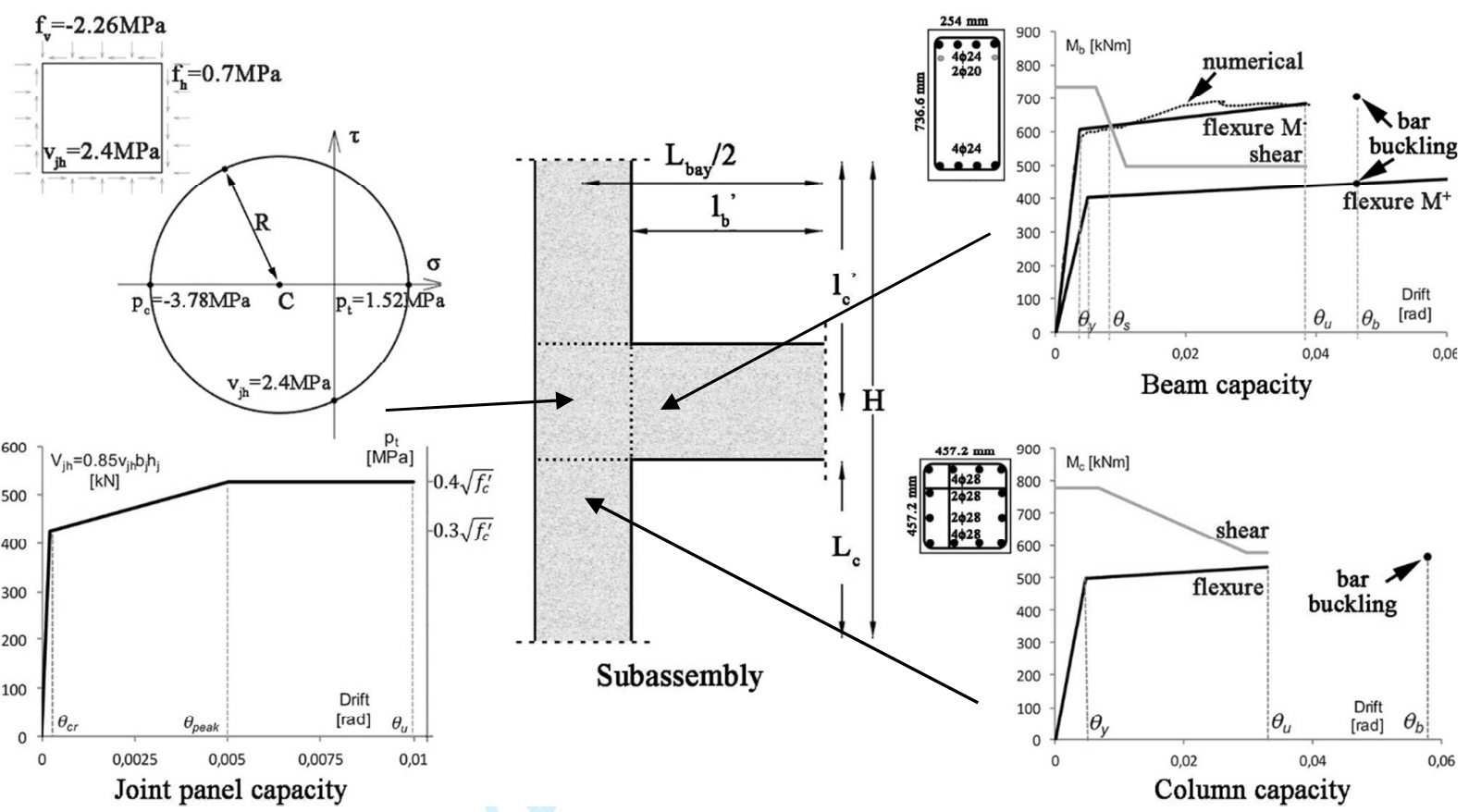

FIGURE 7 Example of evaluation of member capacity in a beam-column joint subassembly (corner joint A1, Frame 1-Floor 1). 


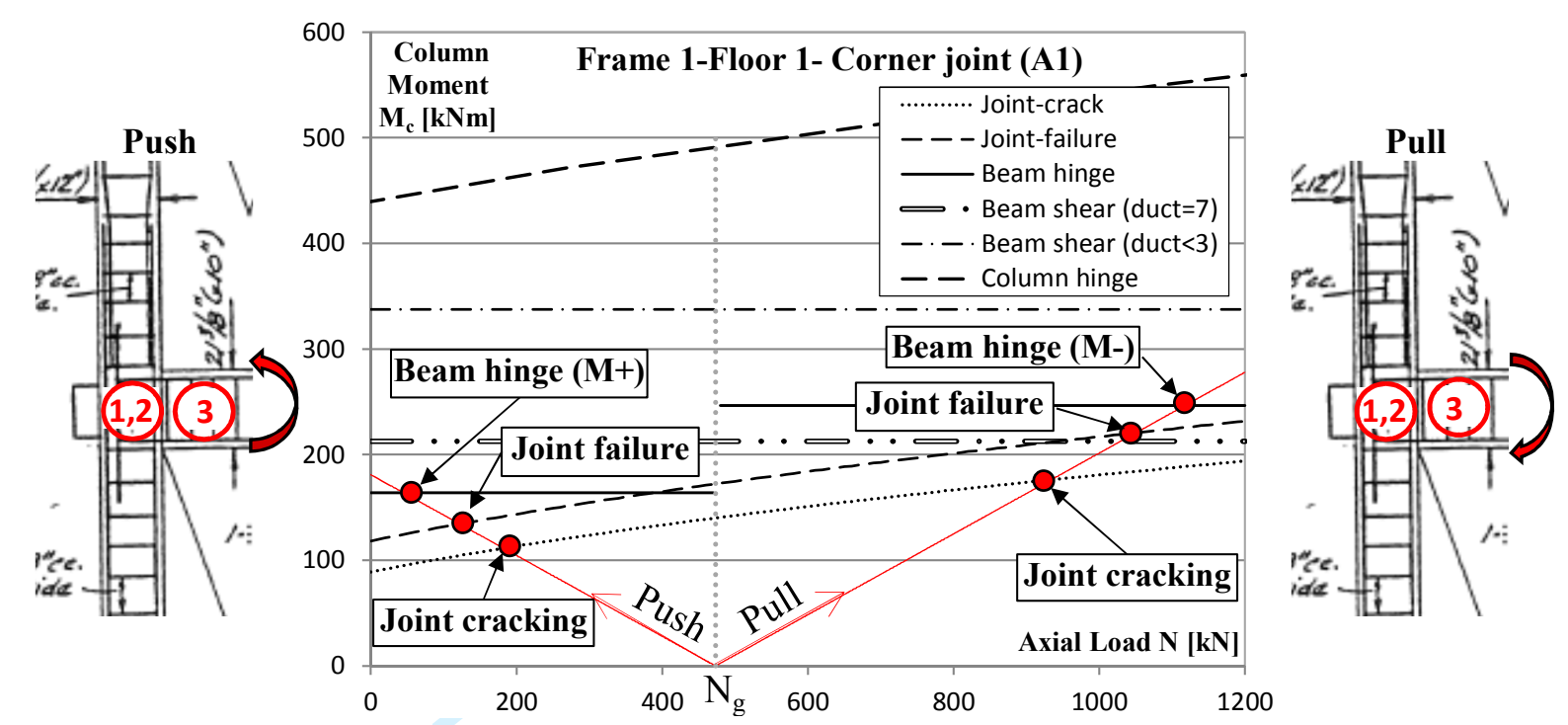

FIGURE 8 Strength hierarchy for the exterior joint A1 at level 1. 


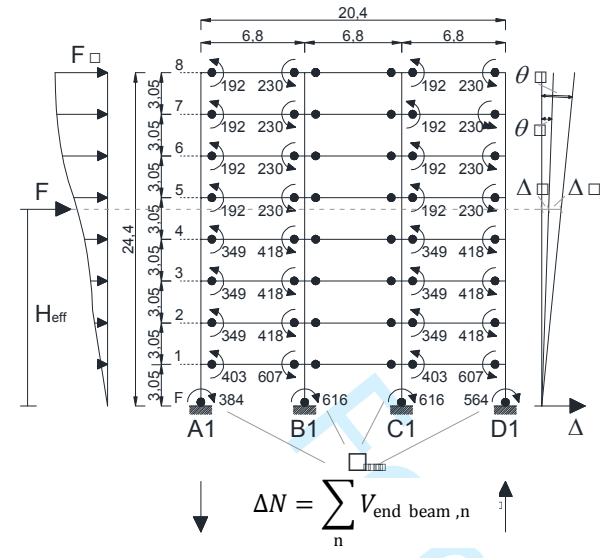

OTM, $1=\mathrm{V}_{\mathrm{b}, 1} * \mathrm{H}_{\mathrm{eff}}=\sum_{\mathrm{i}} M_{\mathrm{col}, \mathrm{i}}+\left(\sum_{\mathrm{n}} V_{\text {end beam, } \mathrm{n}}\right)=$ $=2180+(788.3) 20.4=18261 \mathrm{kNm}$

$\mathrm{H}_{\mathrm{eff}}=[0.64-0.0125(n-4)] H=14.4 \mathrm{~m}$ $\mathrm{V}_{b, 1}=0 \mathrm{TM}, 1 / \mathrm{H}_{\mathrm{eff}}=\frac{18261}{14.4}=1268 \mathrm{kN}$ $\Delta_{y}=\min \left(\theta_{y, \text { beam }}\right) \cdot \mathrm{H}_{\mathrm{eff}}=$ $=0.0037 \cdot 14.4=53 \mathrm{~mm}$

$\Delta_{u}=\min \left(\theta_{u, \text { beam }}\right) \cdot \mathrm{H}_{\mathrm{eff}}=$ $=0.01 \cdot 14.4=144 \mathrm{~mm}$

(a) Beam sidesway

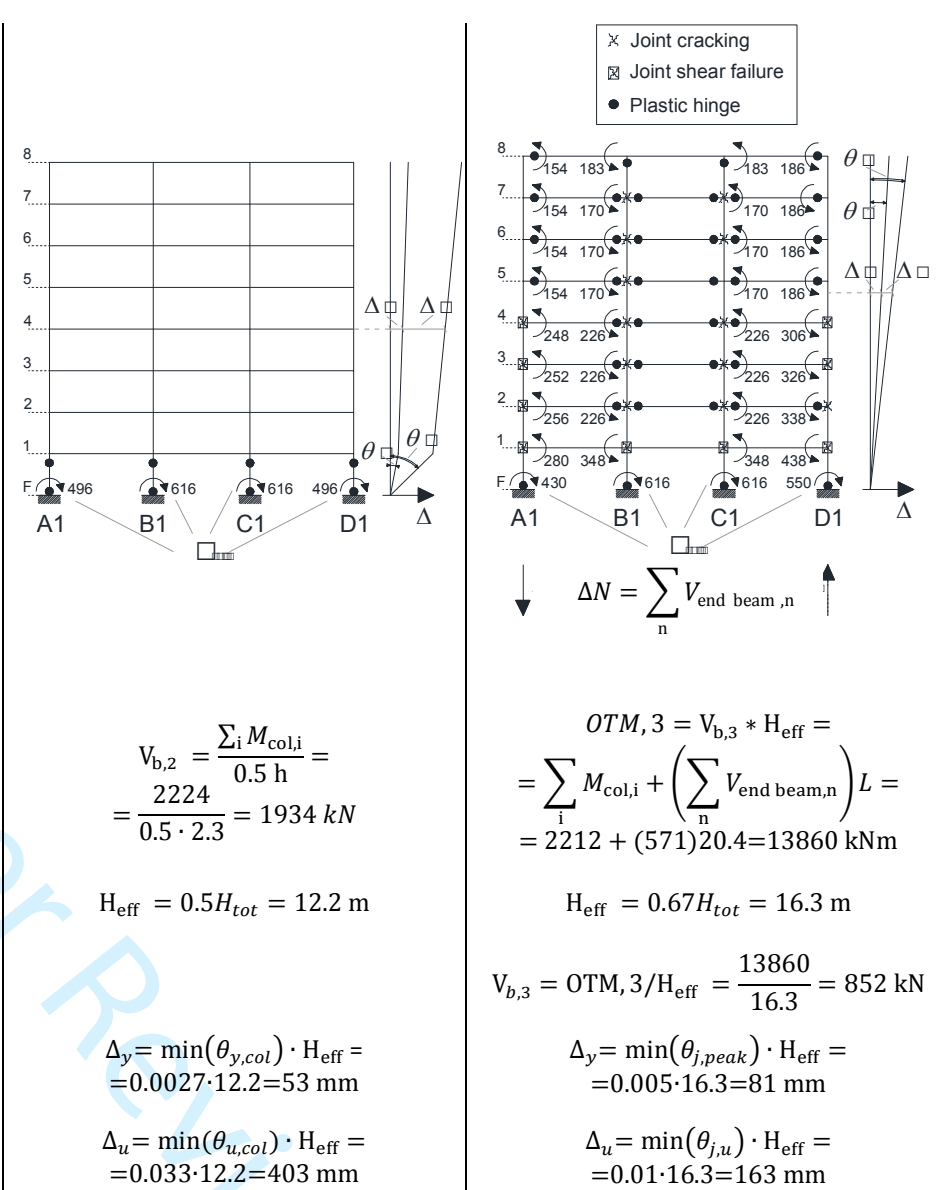

(b) Column sidesway

(c) Mixed sidesway

FIGURE 9 Force and displacement distribution of Frame 1: (a) Beam sidesway; (b) Column sidesway; (c) Mixed sidesway. 


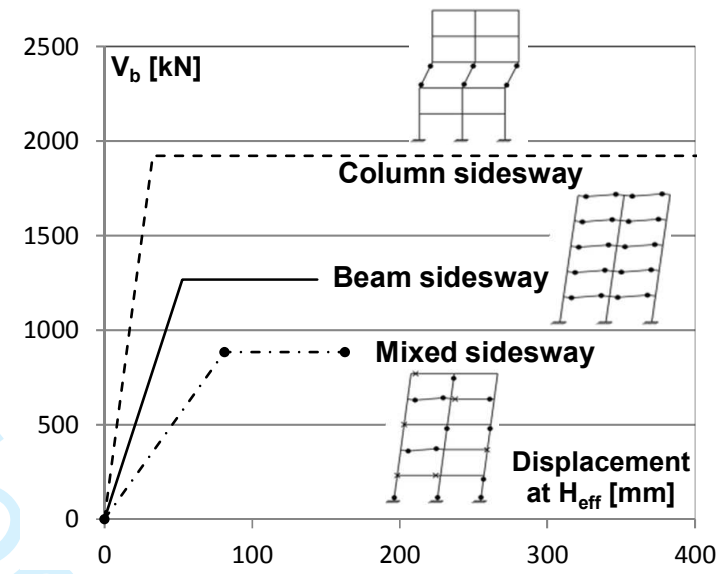

FIGURE 10 Lateral capacity curves of Frame 1. 

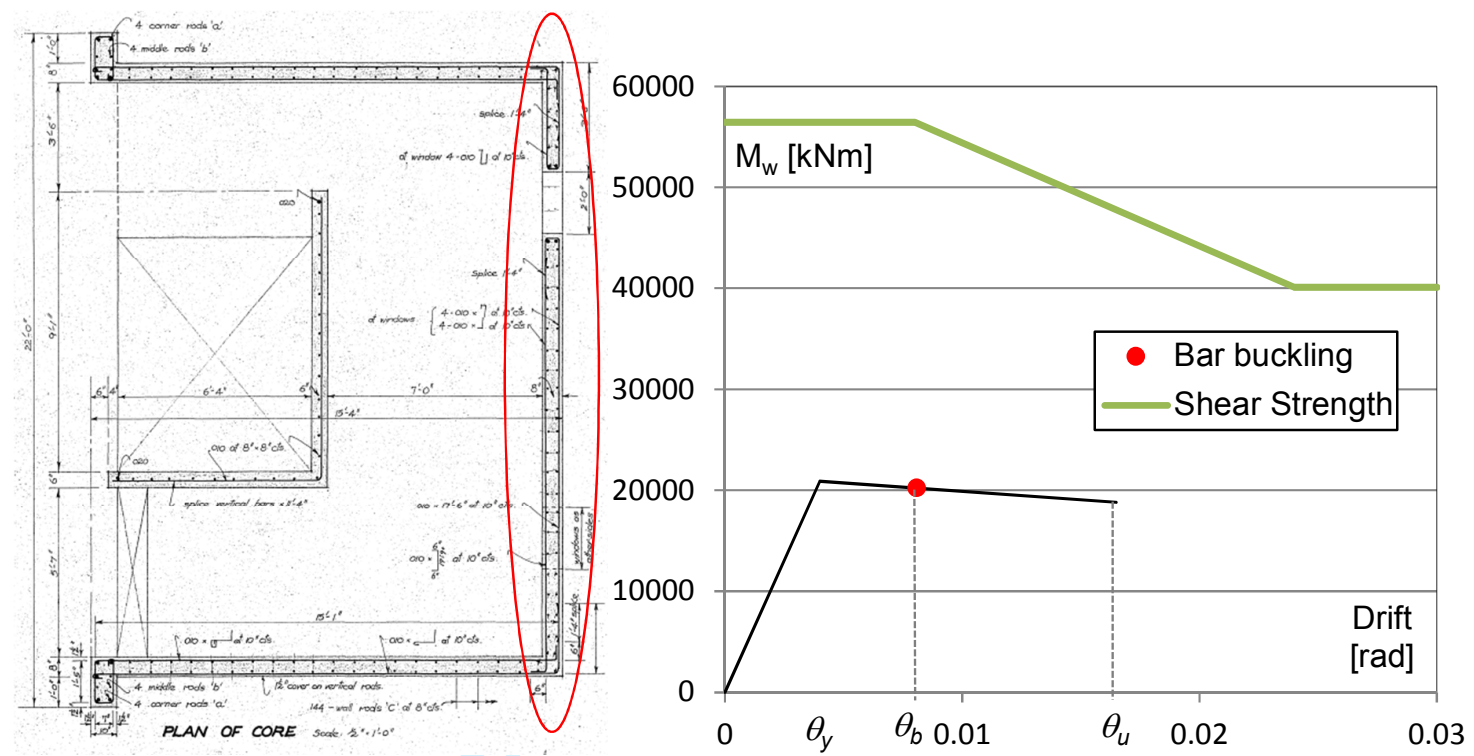

FIGURE 11 C-wall reinforcement detail and moment-curvature capacity of wall web at the ground floor. 


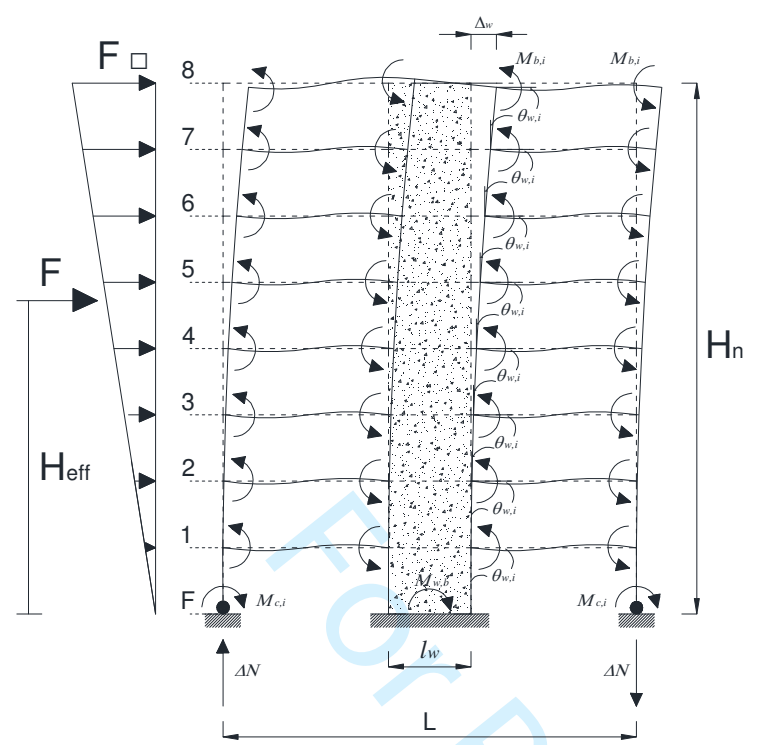

a)

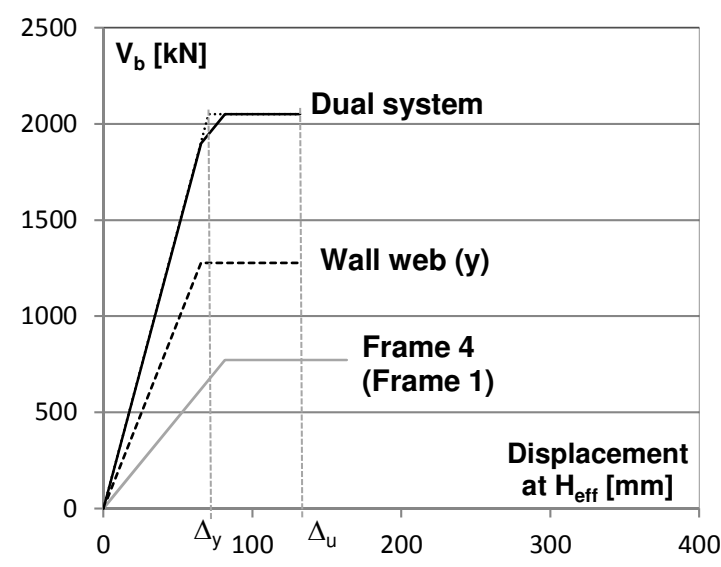

b)

FIGURE 12 Lateral capacity of the dual system: (a) plastic mechanism assumed for the calculations; (b) pushover curve. 


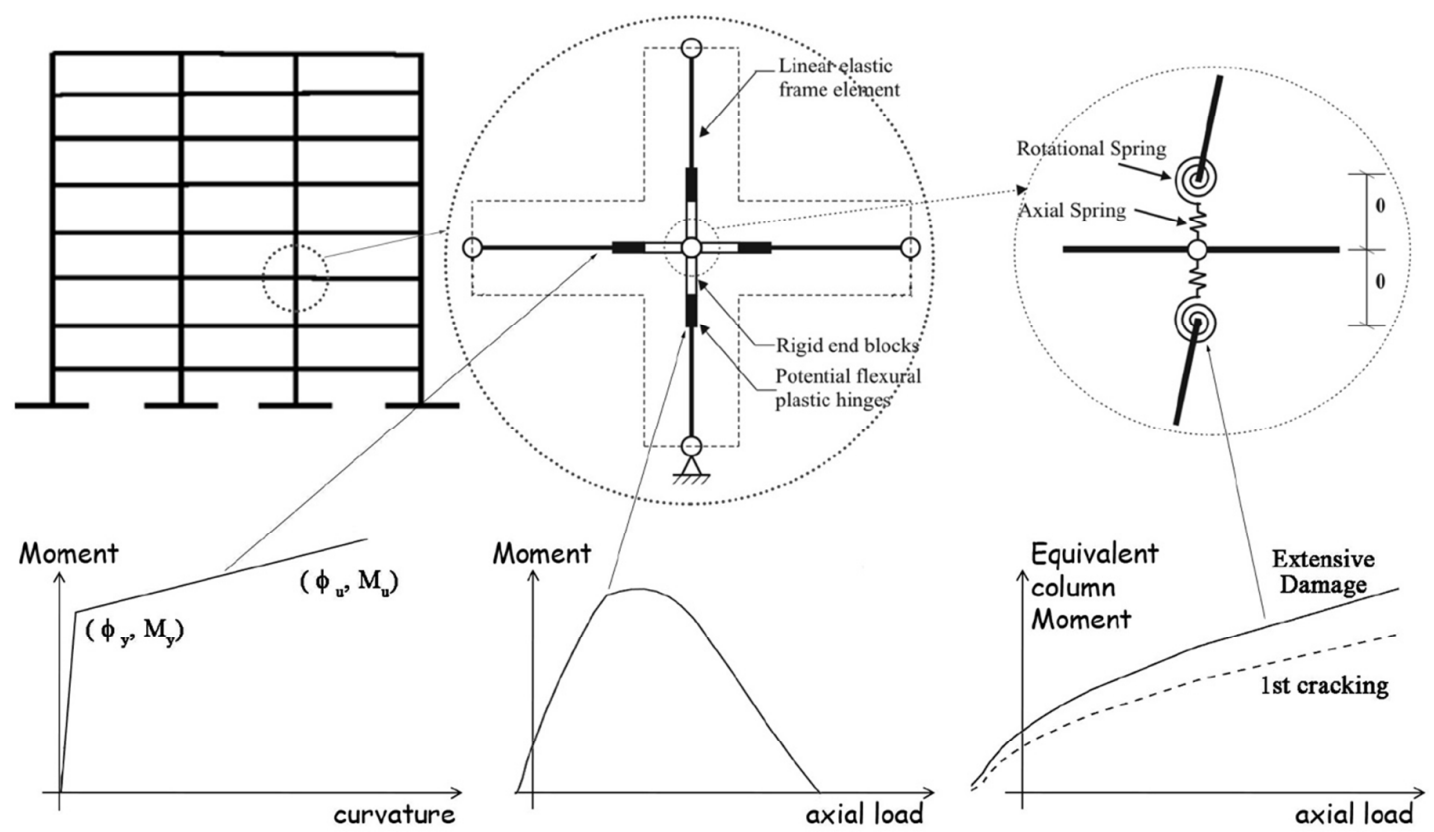

FIGURE 13 Modelling strategy (after Pampanin et al. [2003]). 
a) Frame 1

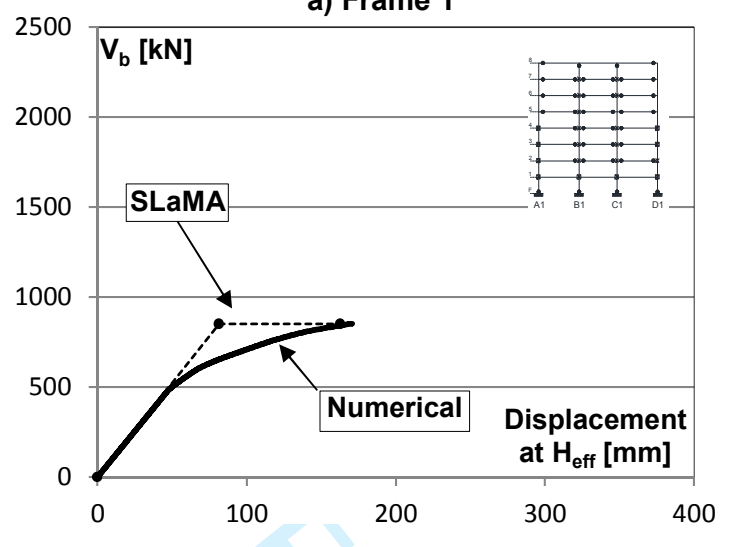

c) Dual system

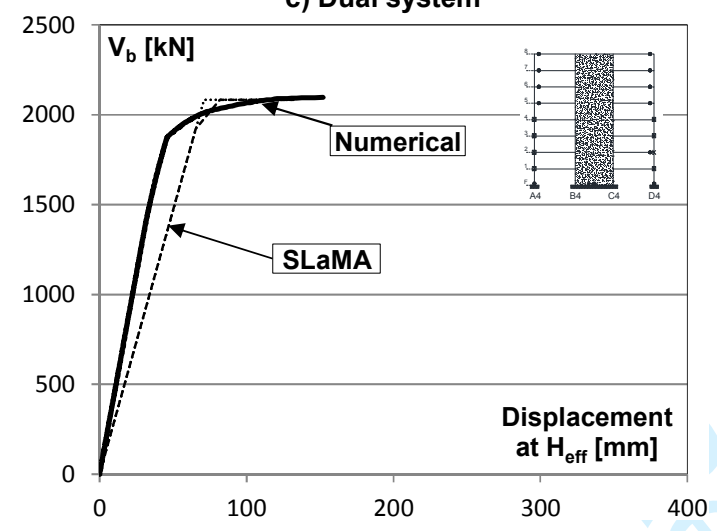

b) Frame A

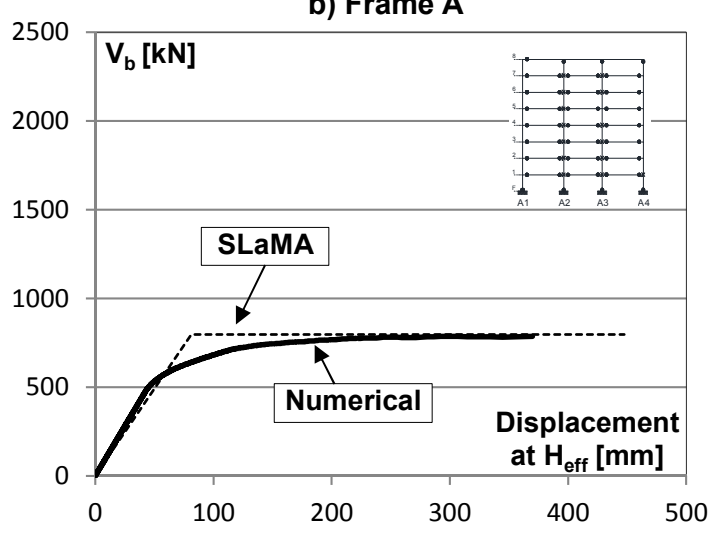

d) Wall Flange

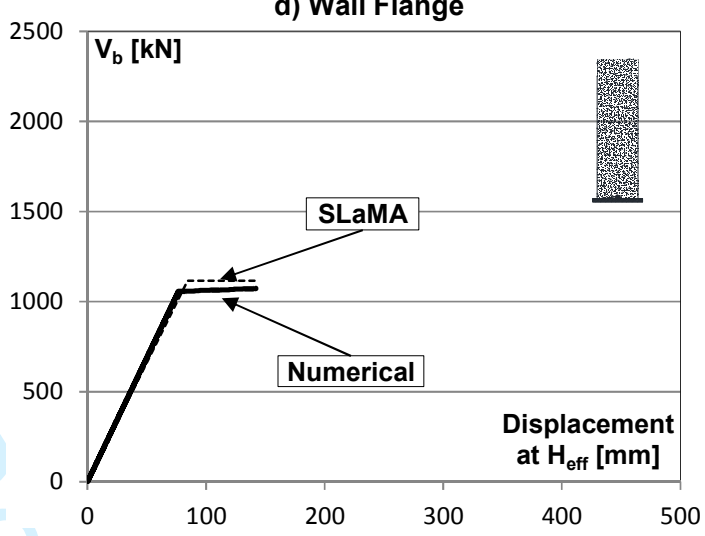

FIGURE 14 Comparison of SLaMA vs Numerical capacity curves for: a) Frame 1; b) Frame A; c) dual system; and d) wall flange. 
FRAME 1

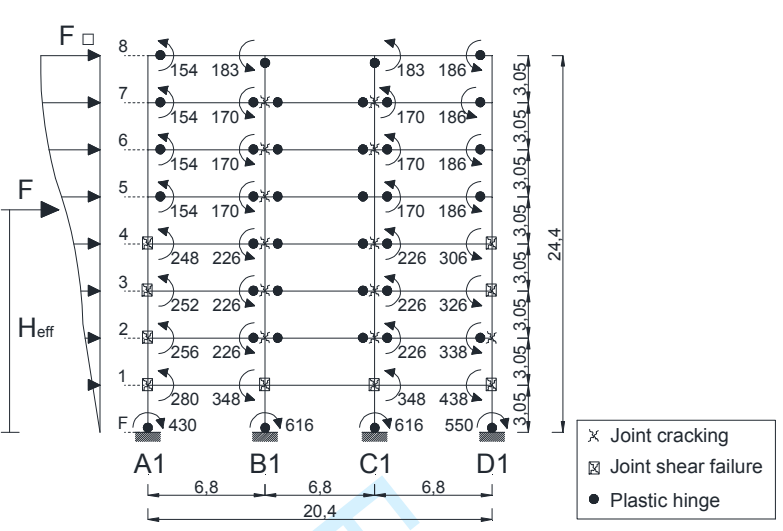

a)

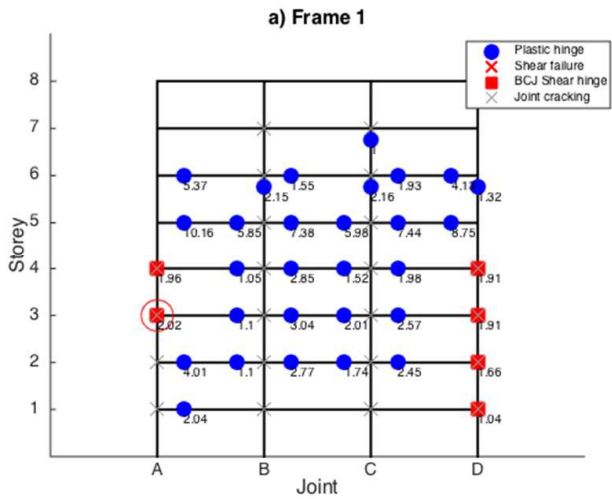

b)

FIGURE 15 Frame 1 plastic mechanism: (a) SLaMA; (b) numerical pushover. 
FRAME A

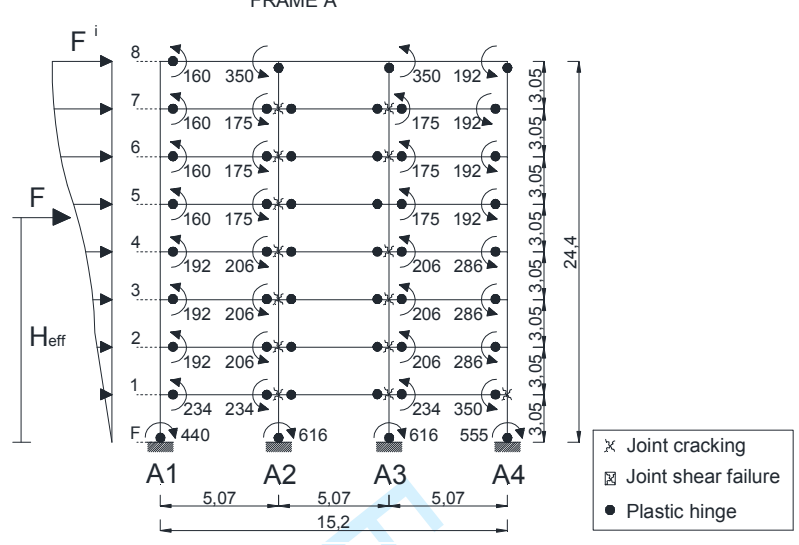

a)

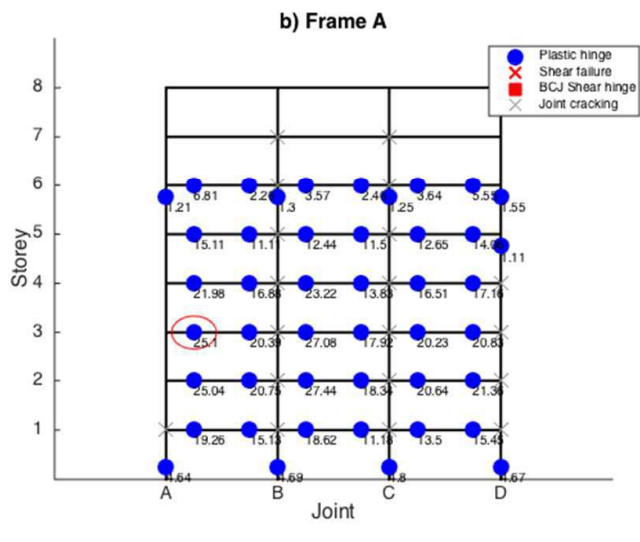

b)

FIGURE 16 Frame A plastic mechanism: (a) SLaMA; (b) numerical pushover. 

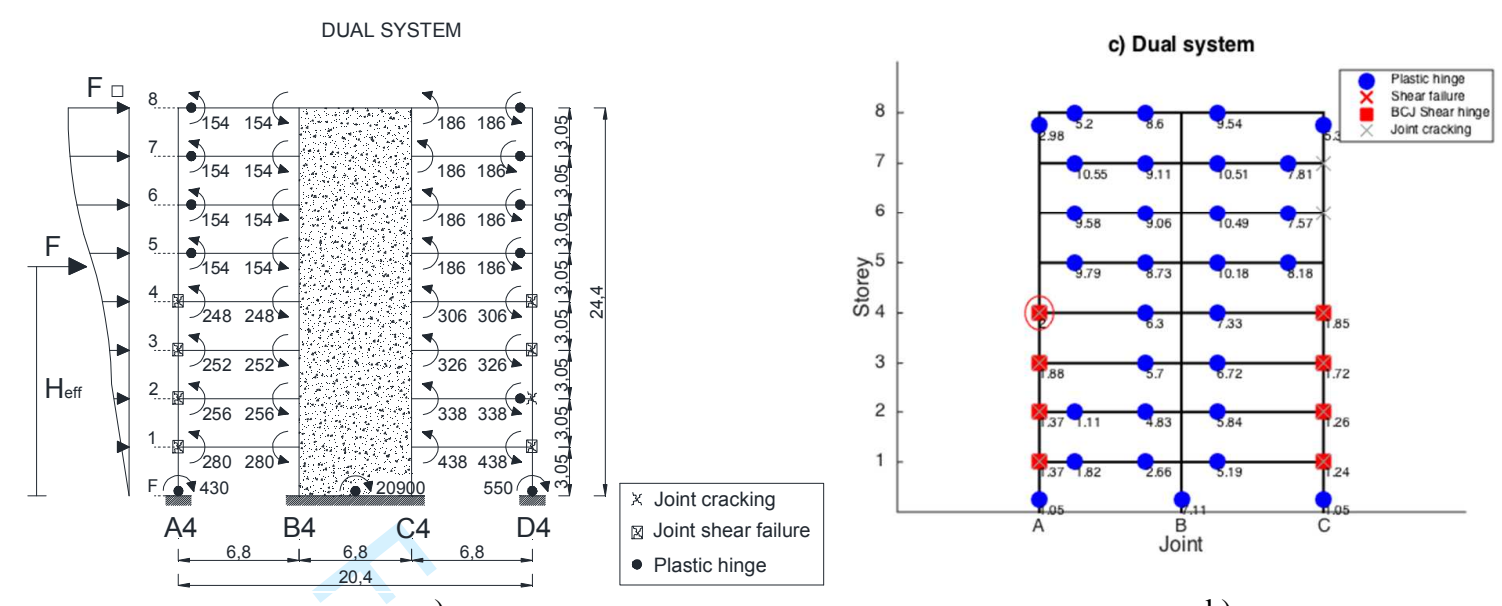

a)

b)

FIGURE 17 Dual system plastic mechanism: (a) SLaMA; (b) numerical pushover. 


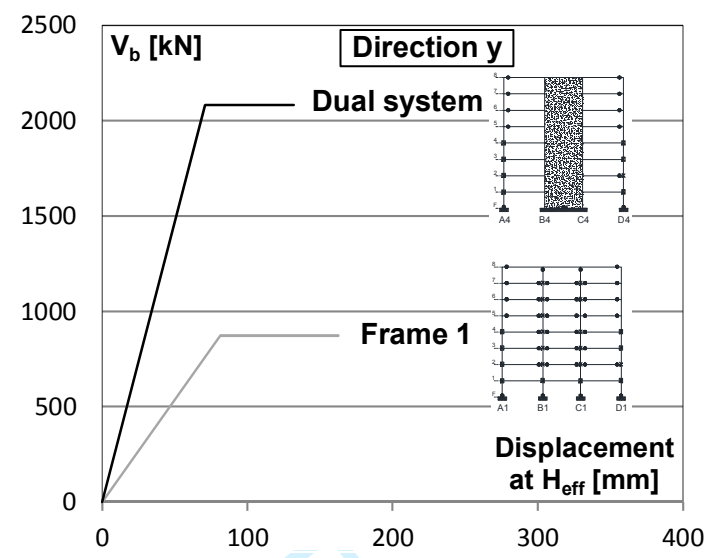

a)

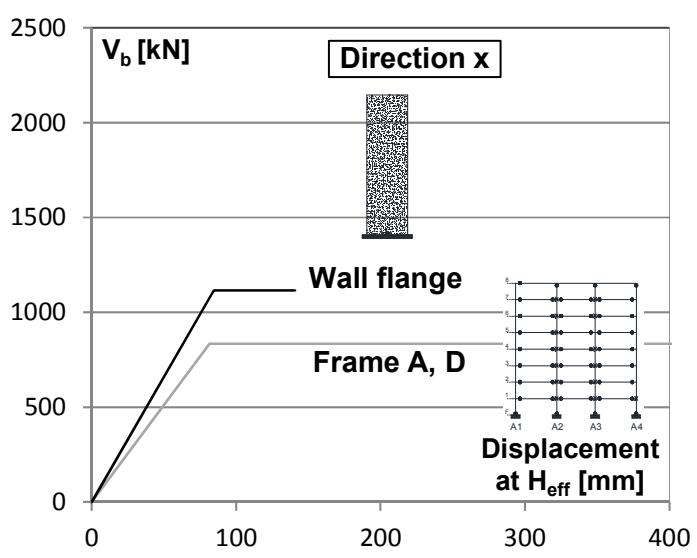

b)

FIGURE 18 Lateral capacity of resisting systems in the (a) y direction and (b) x direction. 


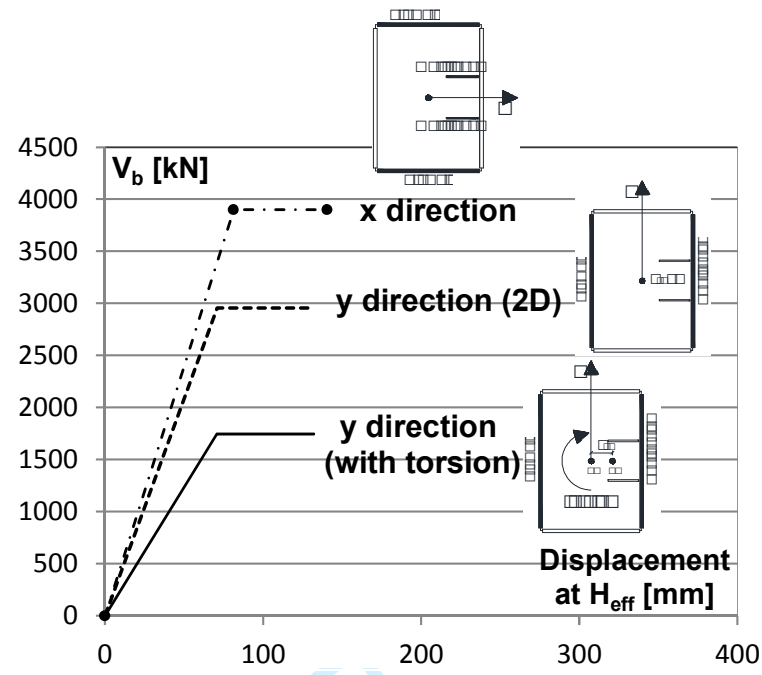

a)

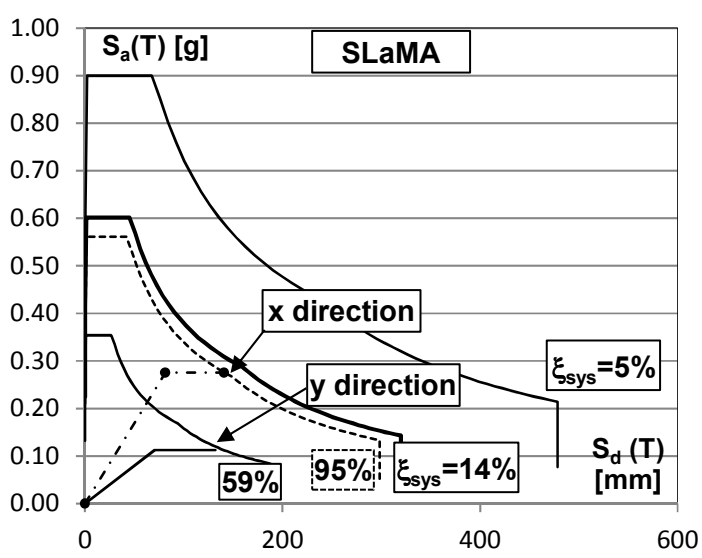

b)

FIGURE 19 (a) Lateral capacity of resisting systems in the two directions and (b) Demand vs. Capacity in the ADRS format for both directions with torsion. 


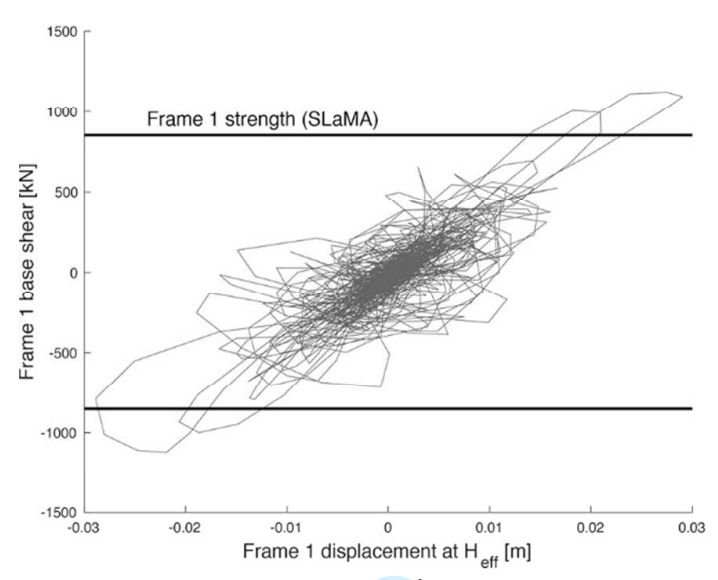

a)

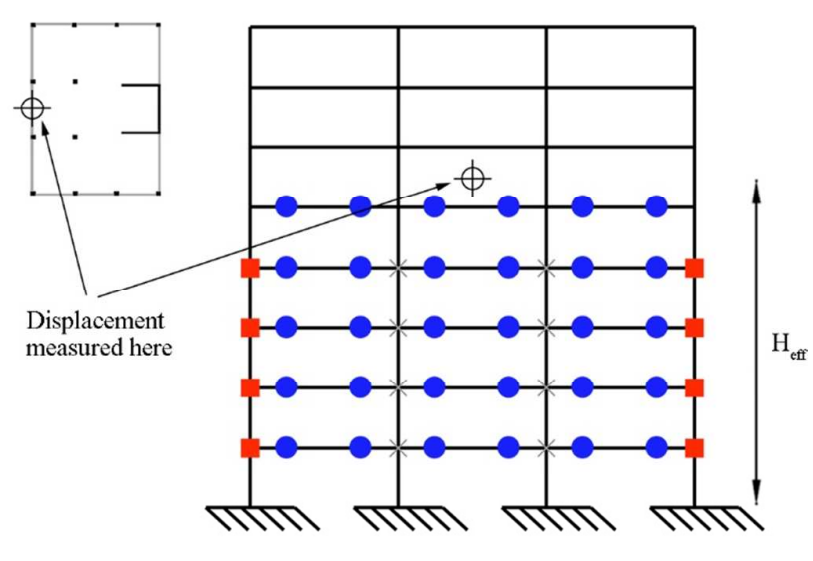

b)

FIGURE 20 Frame 1 NLTH response: (a) base shear vs displacement at the effective height; (b) failure mechanism. 